\title{
A Novel Approach for the Power Ramping Metrics
}

\author{
M. Saber Eltohamy ${ }^{1}$, M. Said Abdel Moteleb², Hossam Talaat ${ }^{3}$, S. Fouad Mekhemar ${ }^{4}$, Walid Omran \\ ${ }^{1}$ Department of Power Electronics and Energy Conversion, Electronics Research Institute (postgraduate student at Ain \\ Shams University), Egypt \\ ${ }^{2}$ Department of Power Electronics and Energy Conversion, Electronics Research Institute, Egypt \\ ${ }^{3,4}$ Department of Electrical Engineering, Future University in Egypt, Egypt \\ ${ }^{5}$ Department of Engineering and Materials Science, Faculty of Engineering and Materials Science, German University in \\ Cairo, Egypt
}

\begin{tabular}{l} 
Article Info \\
\hline Article history: \\
Received Jul 12, 2020 \\
Revised May 27, 2021 \\
Accepted June 12, 2021 \\
\hline
\end{tabular}

\section{Keywords:}

Power system flexibility

Ramp definition

Variable renewable generation

Energy management

Ramp metrics

\begin{abstract}
One of the biggest concerns associated with incorporating a large amount of renewable energy into power systems is the need to cope with significant ramps in renewable power output. Power system operators need to have statistical information on the power ramping features of renewable generation, load, and net-load that can be used to mitigate ramping events in the case of a large forecast error to ensure the power system's flexibility and reliability; on the other hand, for economic considerations. So far, there is no consensus on a precise definition for the ramp event and so far there are hardly any metrics describing the ramping features of a power system. The paper introduces new metrics describing the power ramping features in a power system. The new metrics are ramp regularity factor (RRF), ramp intensity factor (RIF), and maximum ramp ratio (MRR). In addition, the coefficient of variation (CV) is used to characterize the average value of power ramps. The new ramp metrics are applied to the output power of Belgium's aggregated wind farms in 2017 and 2018. The results obtained by comparing the two years demonstrate that the two years have the same ramping behavior, although the average installed wind capacity has been increased. The new metrics can also be applied to other renewable sources (PV, tidal power, etc.), load, and net-load at any stage of operation.
\end{abstract}

Copyright $(2021$ Institute of Advanced Engineering and Science. All rights reserved.

\section{Corresponding Author:}

Mohammed Saber Eltohamy,

Department of Power Electronics and Energy Conversion,

Electronics Research Institute,

Joseph Tito St, Huckstep, Qism El-Nozha, Cairo Governorate, 12622, Egypt.

Email: mohammed_saber@eri.sci.eg

\section{NOMENCLATURE}

\begin{tabular}{|c|c|c|c|}
\hline$C V_{d}$ & $\begin{array}{l}\text { The coefficient of variation of daily } \\
\text { power ramps }\end{array}$ & $M R R_{d}$ & $\begin{array}{l}\text { The maximum ramp ratio of daily power } \\
\text { ramps }\end{array}$ \\
\hline$C V_{t}$ & $\begin{array}{l}\text { The coefficient of variation of power } \\
\text { ramps at an observation time } t\end{array}$ & $M R R_{t}$ & $\begin{array}{l}\text { The maximum ramp ratio of power ramps } \\
\text { at an observation time } t\end{array}$ \\
\hline$C V_{t+/-}$ & $\begin{array}{l}\text { The coefficient of variation of upward or } \\
\text { downward power ramps at an observation }\end{array}$ & $n, \mathrm{~N}$ & $\begin{array}{l}\text { A counter for historical readings and the } \\
\text { total number of historical readings }\end{array}$ \\
\hline & time $t$ & $n_{+/-}, N_{+/-}$ & A counter for upward and downward \\
\hline$d_{n}$ & The total number of days & & $\begin{array}{l}\text { ramps in historical readings and the total } \\
\text { number }\end{array}$ \\
\hline $\boldsymbol{h}$ & The length of the power curve time series. & $P_{M a x}$ & The maximum load (or net-load) value \\
\hline is $\Delta p_{\text {avgd }}$ & $\begin{array}{l}\text { The average value of power ramps over a } \\
\text { certain number of days }\end{array}$ & $P\left(N_{+/-}\right)$ & $\begin{array}{l}\text { Probability of occurrence of a ramp event } \\
\text { with a certain direction }\end{array}$ \\
\hline his $\sigma_{d}$ & $\begin{array}{l}\text { The standard deviation of power ramps } \\
\text { over a certain number of days }\end{array}$ & $P_{R}$ & Rated power of the case study considered \\
\hline$\Delta \boldsymbol{p}_{\operatorname{maxd}+/-}$ & The maximum upward and downward & $P R R_{\text {val }}$ & the power ramp rate threshold value \\
\hline
\end{tabular}




\begin{tabular}{|c|c|}
\hline$P(t)$ & The output power at time $t$ from wind/PV \\
\hline$P_{\text {val }}$ & The threshold value of the power ramp \\
\hline$P_{W(\text { or } S)}$ & The installed wind (solar) capacity \\
\hline$R I F_{d}$ & $\begin{array}{l}\text { The ramp intensity factor of daily power } \\
\text { ramps }\end{array}$ \\
\hline $\boldsymbol{R I} \boldsymbol{F}_{t}$ & $\begin{array}{l}\text { The ramp intensity factor of power ramps } \\
\text { at observation time } t\end{array}$ \\
\hline$R R F_{d}$ & $\begin{array}{l}\text { The ramp regularity factor for daily } \\
\text { power ramps }\end{array}$ \\
\hline$R R F_{t}$ & $\begin{array}{l}\text { The ramp regularity factor of power } \\
\text { ramps at an observation time } t\end{array}$ \\
\hline$t$ & The observation time \\
\hline$\Delta p$ & $\begin{array}{l}\text { The power ramp in a studied time interval } \\
\Delta t\end{array}$ \\
\hline$\Delta \boldsymbol{p}_{\text {avgd }}, \Delta \boldsymbol{p}_{\text {avgt }}$ & $\begin{array}{l}\text { The average value of power ramps in a } \\
\text { studied day and at an observation time } t\end{array}$ \\
\hline$\Delta \boldsymbol{p}_{\text {avgd }+/-}$ & $\begin{array}{l}\text { The average value of upward and } \\
\text { downward power ramps of a studied day }\end{array}$ \\
\hline
\end{tabular}

\begin{tabular}{|c|c|}
\hline$\Delta \boldsymbol{p}_{\text {avgt }+/-}$ & $\begin{array}{l}\text { The average value of upward and } \\
\text { downward power ramps at an observation } \\
\text { time } t\end{array}$ \\
\hline$\Delta p_{\operatorname{maxd}+/-}$ & $\begin{array}{l}\text { The maximum value of upward and } \\
\text { downward power ramps of a studied day }\end{array}$ \\
\hline$\Delta p_{\text {maxt }+/-}$ & $\begin{array}{l}\text { The maximum value of upward and } \\
\text { downward power ramps at an observation } \\
\text { time } t \text {. }\end{array}$ \\
\hline$\Delta p_{n}$ & $\begin{array}{l}\text { The historical readings of power ramps at } \\
\text { a selected observation time } t \text {. }\end{array}$ \\
\hline$\Delta t$ & The studied time interval. \\
\hline$\mu$ & The average value of the population \\
\hline$\sigma_{d}, \sigma_{t}$ & $\begin{array}{l}\text { The standard deviation of power ramps in } \\
\text { a studied day and at a selected } \\
\text { observation time } t\end{array}$ \\
\hline$\sigma_{d+/-}, \sigma_{t+/-}$ & $\begin{array}{l}\text { The standard deviation of upward and } \\
\text { downward power ramps in a studied day } \\
\text { and at a selected observation time } t\end{array}$ \\
\hline
\end{tabular}

\section{INTRODUCTION}

The power systems are gradually increasing renewable generation (RG) as clean, plentiful, low-cost, and permanent sources of energy compared to fossil fuels. Moreover, the utilities need diverse generation resources to enhance system reliability and flexibility. As a result, RG in 2019 represented about $72 \%$ of the overall capacity additions, with wind and solar generation accounting for $90 \%$ of this percentage, as shown in Figure 1[1]. RG, on the other hand, increases the variability and uncertainty in the power system because its output depends on environmental conditions, leading to a modification in the planning studies to find flexible energy sources that can cover fluctuations in RG instead of just finding generation to cover consumption [2].

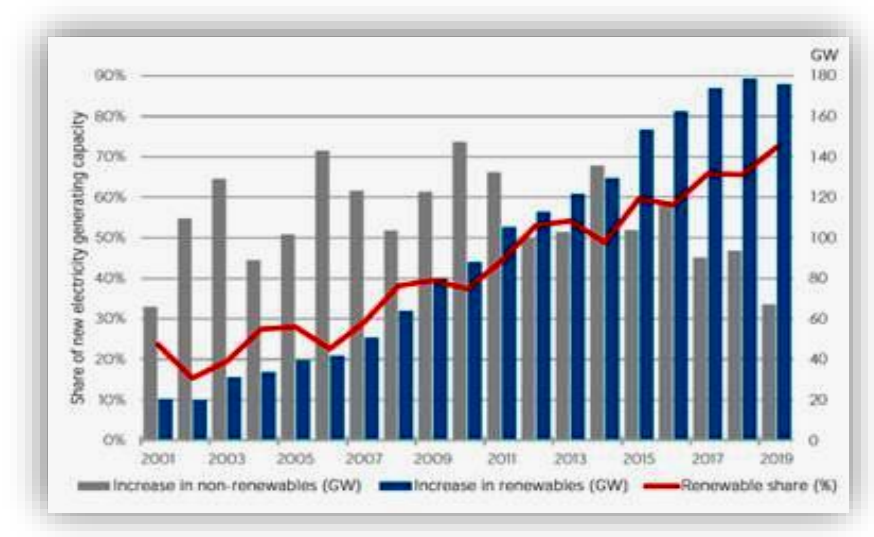

Figure 1. The renewable generation share of annual generation capacity expansion

Power system operators may find it difficult to deal with this variability of power. In [3], the ramp rates of three uncorrelated RGs (wind, solar, and in-stream tidal) were studied besides the average, minimum, and maximum power production to get the optimal combination of their generating capacities. The authors of [4] proposed the intra-hour variability score metric to represent the sum of the absolute values of 1-min variation in both plane of array irradiance and $\mathrm{AC}$ power production, they displayed values for different sites measured for each hour of the day. The authors of [5] proposed a variability index to quantify irradiance, which was formulated as the ratio of the measured irradiance to the reference clear sky irradiance. The results were shown on a daily rather than hourly basis. On clear-sky days, the variability index will be close to one, while it will be low on rainy or overcast days. However, clear days may have low variability index values like rainy and overcast days with low irradiance all day. In addition, the mean annual value of the variability index decreased with an increase in the time interval studied. In [6], universal and natural variability indexes were used for quantifying variations in solar irradiance and PV power output over multiple timescales, the authors illustrated that although PV production is largely dependent on solar irradiance, variations in irradiance cannot fully represent the variability of power. There are many irradiance variability metrics, such as the daily aggregate ramp rate, the variability score, and the standard deviation of irradiance [7]. However, the irradiance variability metrics are based on horizontal irradiance variability, whereas the PV modules are tilted surfaces 
and the irradiance variability on the inclined planes is higher than on the horizontal planes [8]. The author of [9] used the Lorenz curve that is traditionally used in economics for measuring the variability of incomes, to show the variability of PV plant output power. However, the results just presented the Gini coefficient for daily and monthly power variations rather than short-term fluctuations and did not quantify the magnitude and direction of such variations. The authors define the relative output variability of a PV fleet in [10] as the ratio of a PV fleet's output variability to the output variability of the same fleet but concentrated at a single location. The results showed a reduction in relative variability by dispersing the fleet over a wide area. In [11], an analysis of the instantaneous output power at 4-second intervals of four PV plants was performed. The results of the variability study showed that over $95 \%$ of the time, these very short-term output changes were within a $1 \mathrm{MW}$ fluctuation. Although the effect of PV variability was limited by low PV penetration, the variability of the combined PV output showed an increase in the frequency of higher magnitude variability. Thus, at the higher penetration levels, larger ramping events can be expected from the aggregate PV generation.

The power system operators and planners should have information about the ramping events that occur in the system. In [12], the authors concluded that future research should include the ramp forecasting of variable renewable generation (VRG) into power system operation and planning. However, the forecasting error percentage is still relatively high [13][14], impacting the generation-demand balance and electricity prices [15]. All of the predictive schemes used in [16] forecasted only a small number of ramp events, and work to improve forecasting approaches are still ongoing [17][18]. In [19], just a binary count was done to determine the number of days with a ramp event during a certain period of the day. In [20] based on historical wind power data, the duty ratio of wind power ramp was proposed to quantify intermittency, the results demonstrated that wind power is more intermittent than wind speed, which was also illustrated in [21] by calculating the duty ratio of wind speed. The author concluded in [22] that the predictions of changes in wind speed are uncertain, and the variations in power associated with these predictions are less than the observed variability. In [23], the authors introduced a variability index as the standard deviation of a band-limited signal in a moving window of six hours, this index was insensitive to rapid fluctuations. The authors stated that a high proportion of wind power variability could not be explained by wind speed alone.

In [24], the authors proposed a probabilistic metric that depends on the risk preference of the decisionmakers, to quantify the ranges of wind power output based on the minimum and maximum generation levels at a certain time interval. However, when the dynamic uncertainty intervals produced by the proposed metric were compared to the static one formed by a fixed forecast error of $20 \%$, the results were approximately equal. In addition, the authors only used 3-month data to generate dynamic ranges, while wind power output variability varies with months, seasons, and time of day, so more data will include more information and may generate different ranges of wind power. In [25], the authors proposed the ultra-diurnal variation metric to estimate the portion of ultra-diurnal frequencies of variation, which can be used in selecting the locations of new wind farms. In [26], the authors proposed a metric for sizing the boundary of wind power variability in a studied time interval, which does not depend on the level of forecast error but depends on the statistical analysis. However, the metric did not determine the ramp rate of the power ramps and the three standard deviation rule did not cover $99.7 \%$ of power ramps, because the distribution of power ramps is not normal. In [27], the authors presented a metric for quantifying the cost of the variability of wind power. In [28], the authors illustrated that the higher temporal resolution of wind power captured more variability and led to better estimation of total energy costs. In [29], the authors demonstrated the importance of the mean distance between wind farms and the capacity factor in clarifying the variations in wind generation which increased by raising the capacity factor. In [30], the variability of various renewable energy sources (wind, solar, and wave power) was quantified through the measurement of reserve requirements. While in [31] the authors proposed metrics to examine the variability difference between the independent and combined generation of three RGs (wind, solar, and hydropower). The power systems will need to investigate the effect of increasing shares of VRG on the power ramping behavior. In [32], the ramp characteristic indicators have been proposed for comparing the ramping behavior of VRG in different years. These indicators can be utilized also for comparing the ramping behavior between the power systems in different countries. Statistical analysis of historical data can be used to obtain the ramping characteristics of a variable energy source [33][34]. This paper discusses the different ramp definitions and when the ramp is classified as a ramp event besides the meteorological processes related to ramp events. The main contribution of the paper is the introduction of new metrics that characterize ramping behavior in a power system. These metrics will assist both power system planners and operators in selecting or committing the correct generation. Moreover, based on these metrics, system operators will take appropriate necessary precautions, enabling them to avoid large prediction errors and so improve both the power system flexibility and reliability. 


\section{POWER RAMPS}

\subsection{CHARACTERISTICS FOR RAMP DEFINITIONS}

In [35], the authors stated that the ramp event definition mainly contains two points, a small time scale, and a sharp power change. Several characteristics have been outlined to define, characterize, and identify ramps. In [36], three key characteristics which are direction, magnitude, and duration should be determined to define a ramp. The direction of power ramps may be upward or downward. In [19][37], the ramp event whether it is upward or downward is characterized by a rapid increase or decrease in power output. The ramp event magnitude is user-defined [38], hence a ramp that is a ramp event on one system might not be a ramp event on another. For wind generation, the ramp event magnitude is usually defined as a percentage of the nominal capacity installed or as a megawatt value. The ramp duration is a user-defined parameter that defines the time interval $(\Delta \mathbf{t})$ considered for identifying the ramp in minutes or hours. Different ramp durations have been considered; for example, the author in [19] studied ramp events at time intervals ranging from 5 minutes to 1 hour. The authors in [39][40] related the ramp duration to the magnitude and direction of the identified ramps. For studying the ramp phenomena, the difference between the insignificant ramp and ramp event should be known, a ramp event occurs when the power change for a relatively short period has a large enough magnitude [36][41]. The ramp event may cause severe problems in grid management in the next few hours or days [42]. The insignificant ramp is defined as an upward or downward ramp of a smaller magnitude and can be managed easily.

\subsection{RAMP EVENT DEFINITIONS}

There are several definitions for the ramp event [43][44][45] that may differ according to whether the ramp event is in load or RG (wind or solar). The various definitions of the ramp event are presented below:

- Definition 1: At the start of an interval, the ramp event occurs if the absolute change in the power signal at time $\Delta t$ ahead of the interval is more than a predefined threshold value [19][46].

$$
|\mathrm{P}(\mathrm{t}+\Delta \mathrm{t})-\mathrm{P}(\mathrm{t})|>P_{v a l}
$$

The definition takes only the values on the points of start and end of the interval, while it ignores the ramp events that may occur in between, so the author in [19] extended the previous definition as follows.

- Definition 2: A ramp event occurs in a time interval $\Delta t$ if the difference between the maximum value of power and the minimum in that interval is more than a threshold value:

$$
\operatorname{Max}(\mathrm{P}[\mathrm{t}, \mathrm{t}+\Delta \mathrm{t}])-\operatorname{Min}(\mathrm{P}[\mathrm{t}, \mathrm{t}+\Delta \mathrm{t}])>P_{v a l}
$$

The definition does not consider the speed of power change. In [19], the analysis demonstrated that the two definitions have the same results.

- Definition 3: A ramp event occurs if the ramp rate is more than a predefined power ramp rate threshold value that is measured by MW/min. Definition 3 is more accurate than definitions 1 and 2 because it takes into consideration the slope of the curve or the speed of power change [44].

$$
\frac{|\mathrm{P}(\mathrm{t}+\Delta \mathrm{t})-\mathrm{P}(\mathrm{t})|}{\Delta \mathrm{t}}>P R R_{\text {val }}
$$

In [47], the authors presented four definitions that determine the threshold values of ramp events in load or net-load power signals as a percentage of the maximum load as follows.

\section{a. Definitions of ramp events in load or net-load}

The load and net-load power signals are somewhat stable when compared with solar and wind power signals; therefore load and net-load ramp events are defined with lower threshold values than wind and solar ramp events. Four definitions are presented below for load and net-load ramp events, see Figure 2:

- Definition 1: A ramp event occurs when the change in power of total load (or net-load) is greater than 5\% of the maximum value of load (or net-load);

- Definition 2: As the previous definition but within a period that is less than or equal to four hours;

- Definition 3: A ramp event occurs when the rate of change in total load (or net-load) is greater than $3 \%$ of the maximum value of load (or net-load);

$$
\frac{\Delta \mathrm{P}}{\Delta \mathrm{t}}>0.03 P_{\text {Max }}
$$

- Definition 4: Since the management of upward ramps is more difficult than downward ramps, the upward and downward ramp events have different threshold values. The upward ramp event is defined as definition 2; while the downward ramp is defined when the change is greater than $7 \%$ of the maximum value of load (or net-load) within a period that is less than or equal to four hours. 


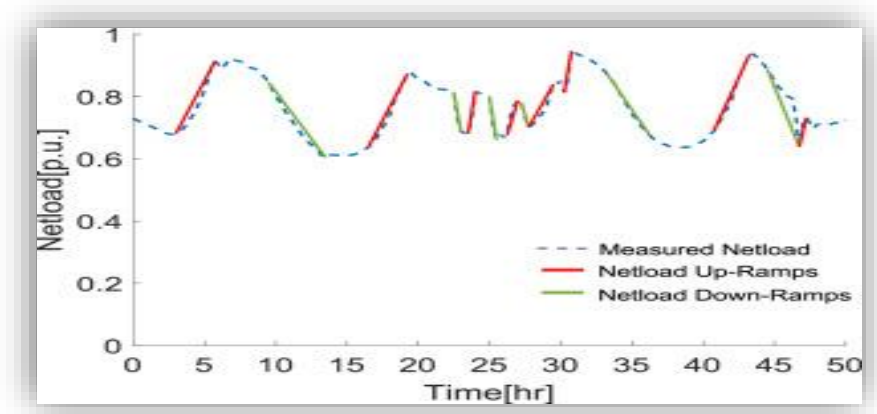

Figure 2. Net-load ramp events[47]

\section{b. Definitions of ramp events in RG (wind or solar power)}

In [36][16], the ramp event in wind power is defined as the change in the output power of a wind farm that is not less than $50 \%$ of the installed capacity within a period that is less than or equal to four hours, as shown in Figure 3.

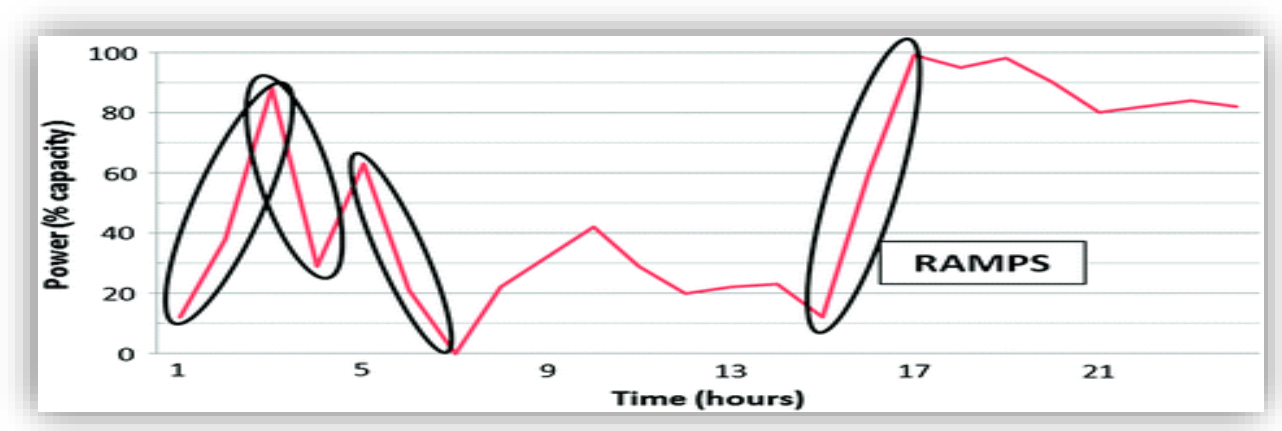

Figure 3. Illustration of wind power ramp events, as defined in [36][48]

In [45], four definitions for wind power ramp events were presented, which determine ramp threshold values as a percentage of the installed wind capacity, which can also be applied to solar power.

- Definition 1: A ramp event occurs when the change in wind power is greater than $20 \%$ of the installed capacity without constraining the ramping duration;

- Definition 2: As the previous definition but within a period that is less than or equal to four hours;

$$
\mathrm{P}(\mathrm{t}+\Delta \mathrm{t})-\mathrm{P}(\mathrm{t})>0.2 P_{W(\text { or } S)} ; \Delta \mathrm{t} \leq 4 h
$$

- Definition 3: A ramp event occurs when the change rate in wind power is greater than $3 \%$ of the installed capacity;

$$
\frac{\Delta \mathrm{P}}{\Delta \mathrm{t}}>0.03 P_{W(\text { or } S)}
$$

- Definition 4: The upward ramp event is defined as definition 2; while the downward ramp is defined when the change in wind power is greater than $15 \%$ of the installed capacity within a period that is less than or equal to four hours. From the grid operators' point of view, the downward ramps in wind (or solar) power are more difficult to be managed than upward ramps because the upward ramps can be managed by adjusting other generators' schedules, or by curtailing wind (or solar) generation if necessary. Whereas if downward ramps occur, the grid operators have to compensate for the shortage of wind (or solar) generation by increasing generation from other generators or by finding other generations to compensate for this deficit and keep the load balanced. Therefore, the percentage of difference threshold for the downward ramps was selected lower than that of upward in definition 4.

For the solar generation, the diurnal upward power ramping that is expected to occur from sunrise to noon and also downward power ramping that is expected to occur from noon to sunset should not be defined as ramp events [47], see Figure 4. 


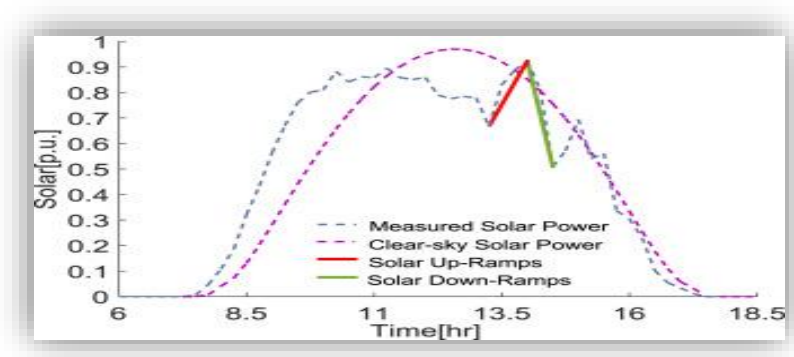

Figure 4. Solar power ramp events[47]

In [49], the collective ramp event describes a scenario in which the majority of solar PV systems concurrently experience a positive or negative ramp event within a given time step. Critical collective ramp events are those that exceed $60 \%$ of the clear-sky potential in one hour. There is no agreement on an accepted formal definition for the ramp event. Table 1 summarizes the different ramp event definitions in wind, solar, net-load, and load power, in which the ramp magnitude threshold varies between $1-75 \%$ from the rated power $\left(\boldsymbol{P}_{R}\right)$, while the ramp duration threshold ranges from 5 minutes to 6 hours. This great divergence in defining the ramp event is due to the difference between the power systems in the capabilities and the flexibility available to meet these ramp events [50][51]. The threshold value could be either a system-dependent or a percentage of the installed nameplate capacity, which is chosen to reflect the amount of power that is difficult to be handled in the given time interval to keep the system balanced. In practice, it is selected based on input from the system operators. It could be different for different regions and could vary over the years to match the changes in load demand and the generation mix.

Table 1. Different ramp event definitions

\begin{tabular}{|c|c|c|c|}
\hline Author & $\Delta p_{0}$ & $\Delta t_{r}$ & Type \\
\hline \multicolumn{4}{|c|}{ Ramp event definition as a percentage of the rated power } \\
\hline \multirow[t]{2}{*}{ N. Cutler [41] } & $75 \%$ & $3 \mathrm{~h}$ & Wind \\
\hline & $65 \%$ & $1 \mathrm{~h}$ & \\
\hline C. W. Potter [39] & $10 \%$ & $1 \mathrm{~h}$ & Wind \\
\hline B. Greaves [36] & $50 \%$ & $4 \mathrm{~h}$ & Wind \\
\hline A. J. Deppe [16] & $50 \%$ & $\leq 4 h$ & Wind \\
\hline K. T. Bradford [42] & $20 \%$ & $1 \mathrm{~h}$ & Wind \\
\hline A. Bossavy [52] & $50 \%$ & $\mathrm{n} / \mathrm{a}$ & Wind \\
\hline C. Kamath [53] & $10-12 \%$ & $30 \mathrm{~min}$ & Wind \\
\hline C. Kamath [53] & $15-20 \%$ & $1 \mathrm{~h}$ & Wind \\
\hline C. Gallego [54] & $\sigma_{g} \boldsymbol{p}_{\boldsymbol{R}}$ & $1 \mathrm{~h}$ & Wind \\
\hline H. Zareipour [55] & $50 \%$ & $10 \mathrm{~min}$ & portfolio \\
\hline R. Girard [56] & $30 \%$ & $\mathrm{n} / \mathrm{a}$ & Wind \\
\hline Q. Yang [57] & $15 \%$ & $1 \mathrm{~h}$ & Wind \\
\hline A. Fernandez [58] & $25 \%$ & $3 h$ & Wind \\
\hline A. Suzuki [59] & $15 \%$ & $6 \mathrm{~h}$ & Wind \\
\hline P. P. Revheim [60] & $30 \%$ & $3 \mathrm{~h}$ & Wind \\
\hline $\begin{array}{c}\text { J. Heckenbergerova } \\
{[61]}\end{array}$ & $50 \%$ & $5 \mathrm{~h}$ & Wind \\
\hline S. J. Wellby [49] & $60 \%$ & $1 \mathrm{~h}$ & Solar \\
\hline M. Abuella [62] & $40 \%$ & $1 \mathrm{~h}$ & Solar \\
\hline D. Gan [63] & $\begin{array}{c}40 \% \text { Upward } \\
30 \% \text { Downward }\end{array}$ & $\begin{array}{l}\mathrm{n} / \mathrm{a} \\
\mathrm{n} / \mathrm{a}\end{array}$ & Wind \\
\hline \multirow[t]{4}{*}{ G. Ren [20] } & $1 \%$ & $5 \mathrm{~min}$ & Wind \\
\hline & $3 \%$ & $15 \mathrm{~min}$ & \\
\hline & $7 \%$ & $30 \mathrm{~min}$ & \\
\hline & $15 \%$ & $1 \mathrm{~h}$ & \\
\hline \multirow[t]{3}{*}{ M. Cui[47] } & $\begin{array}{c}20 \% \text { Upward } \\
15 \% \text { Downward }\end{array}$ & $4 \mathrm{~h}$ & $\begin{array}{l}\text { Wind } \\
\text { (Solar) }\end{array}$ \\
\hline & 5\% Upward & $4 \mathrm{~h}$ & Load \\
\hline & 7\% Downward & & $\begin{array}{l}\text { (net- } \\
\text { load) }\end{array}$ \\
\hline \multicolumn{4}{|c|}{ Ramp event definition as a megawatt value } \\
\hline \multirow[t]{4}{*}{ N. Cutler [64] } & 200 & $30 \mathrm{~min}$ & Wind \\
\hline & 150 Downward & $5 \mathrm{~min}$ & \\
\hline & 150 & $30 \mathrm{~min}$ & \\
\hline & 75 & $30 \mathrm{~min}$ & \\
\hline
\end{tabular}




\subsection{RAMP EVENTS AND METEOROLOGICAL PHENOMENA}

The relation between the occurrence of ramp events and meteorological processes was studied to understand the meteorological phenomena that create ramp events. The authors in [49] explained that the occurrence of critical ramp events in a region is connected to repeatable meteorological phenomena, so the solar zenith angle (SZA) was studied to determine the angles at which critical collective ramp events occurred. SZA provides a reference point for understanding ramping behavior in terms of the location of the sun, see Figure 5(a,b). The authors claimed that by analyzing the frequency of the collective ramp events that occur at a particular SZA range, it would be possible to estimate periods of the day where collective ramp events are most likely to occur. However, relating ramp events by meteorological phenomena is extremely a casedependent problem [65]. In [66], the authors found that the wind ramp events are associated with a local meteorological phenomenon is known as the Föhn wind event and the power ramps varied considerably with season. The authors in [67] distinguished between the meteorological processes that produce upward ramp events and downward ramp events. The meteorological processes related to ramp-up events were defined as the thunderstorm outflow, cold front, sea breezes, and onset of mountain wave events, while those related to ramp-down events were defined as the warm front, boundary stabilization, and relaxation after the cold front.

In [68], the major phenomena related to the ramp events such as cross-mountain flows, shallow cold air, and cold surge events were described. The authors stated that the ramp-up events are happening mostly from May to July and ramp-down events in the period from August to January. Whereas it was found in [19] that both upward and downward ramp events occurred mostly in the afternoon than in the morning and occurred mostly in months from March to August. In [16], only 34\% of ramp events were caused by frontal passages and thunderstorms phenomena, while a high percentage of ramp events could not be explained.

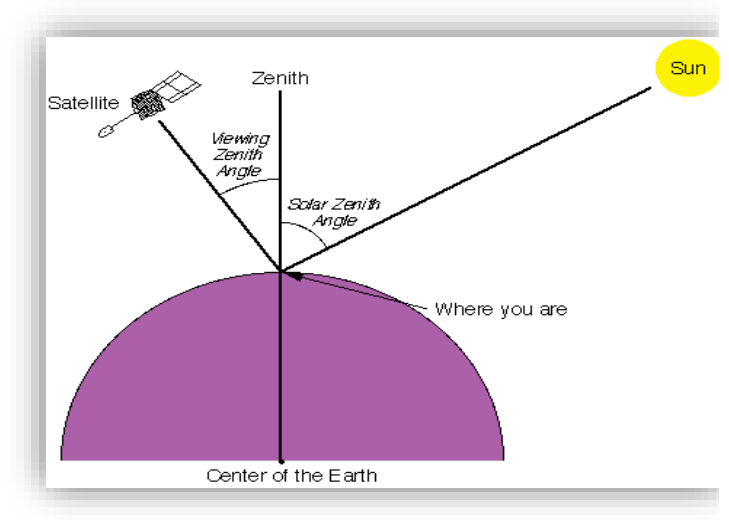

(a)

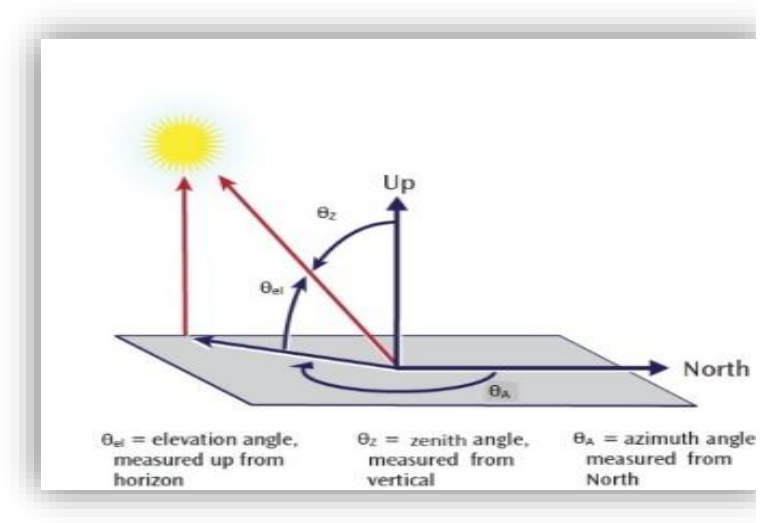

(b)

Figure 5(a, b). Figure (5 a) Schematic illustration of SZA and Viewing Zenith Angle (VZA) for observations from the satellite-based instrument, Figure ( 5 b) Solar Zenith, azimuth, and elevation Angles

\subsection{RAMP METRICS}

So far, there is no consensus on an accurate definition for the ramp event and so far, there are hardly any metrics describing the ramping features in a power system. In this section, new ramp metrics will be presented to describe the power ramping behavior in the system. These metrics can provide power system planners and operators with a description and awareness of system power ramps that occurred during the studied interval, which can be used to commit or dispatch the appropriate generation for these ramp events in the event of a large forecasting error, thereby increasing system flexibility and reliability. The new metrics are ramp regularity factor $(\boldsymbol{R} \boldsymbol{R} \boldsymbol{F})$, ramp intensity factor $(\boldsymbol{R I F})$, and maximum ramp ratio $(\boldsymbol{M R R})$. Also, the coefficient of variation $(\boldsymbol{C} V)$ will be reused in describing the average value of power ramps. The new metrics can be used to analyze the ramping features in load, net-load, PV, and wind power signals. In each metric, the analysis of power signal time series will take two directions as follows:

1. Vertical analysis direction of power signal time series: In which the ramp metrics are calculated for each observation time $t$ in the power signal time series, where the historical readings are used to calculate the power ramps that occurred at a certain observation time t during a studied time interval $\Delta \mathbf{t}$. After that, the power ramps are analyzed to calculate the ramp metrics then moving to the next observation time.

2. Horizontal analysis direction of power signal time series: In which the ramp metrics are calculated by analyzing the historic daily ramp readings during the studied time interval $\Delta \mathbf{t}$ over a certain week, month, season, or year. 
The studied time interval $\Delta \mathbf{t}$ is chosen by the power system operator to analyze the ramping behavior in a power system according to the studied operating stage.

\section{a. The coefficient of variation $(\mathrm{CV})$ :}

The CV was used to measure the spread of a set of data. It is defined as the ratio of the standard deviation $(\sigma)$ to the mean $(\mu)$. The $\mathrm{CV}$ was proposed to compare the variability in different distributions to show the extent of variability in relation to the mean of the population [69][70]. The value of CV that is less than one indicates low variance, while the $\mathrm{CV}$ value that is more than one indicates high variance.

$$
C V=\frac{\sigma}{\mu}
$$

In power systems, the coefficient of variation can be reused to describe the ramping behavior in the power signal. The coefficient of variation informs the power system operators or planners about to what extent they can rely on the average value of power ramps within the studied time interval $\Delta t$. If the value of $\boldsymbol{C} \boldsymbol{V}$ within a studied time interval is less than one, the average value well describes the power ramps in that time interval. While if the value of $\boldsymbol{C} \boldsymbol{V}$ is more than one, the average value does not describe correctly the power change in that time interval, indicating a high level of variation in ramp readings. The $\boldsymbol{C} \boldsymbol{V}$ can be used also in comparing the variability of different power systems. According to the two directions of analysis explained before, the values of $\boldsymbol{C} \boldsymbol{V}$ will be calculated for each direction as follows.

1. The coefficient of variation of power ramps at an observation time $t\left(C V_{t}\right)$ i.e. Vertical analysis direction: It is the ratio between the standard deviation $\left(\boldsymbol{\sigma}_{\boldsymbol{t}}\right)$ and the average $\left(\Delta \boldsymbol{p}_{\text {avgt }}\right)$ of historical power ramps within the studied time interval $(\Delta \mathbf{t})$ at an observation time $\mathbf{t}$, which can be expressed as follows:

$$
C V_{t}=\frac{\sigma_{t}}{\Delta p_{\text {avgt }}}
$$

Where the average value and the standard deviation are calculated as follows:

The historical readings of power are used to calculate the power ramps $\left(\boldsymbol{\Delta} \boldsymbol{p}_{\boldsymbol{n}}\right)$ that occurred within a selected time interval $(\Delta \mathrm{t})$ at a selected observation time $t$ as in "9".

$$
\Delta \mathrm{P}_{n}=\mathrm{P}\left(t_{n}+\Delta \mathrm{t}\right)-\mathrm{P}\left(\mathrm{t}_{\mathrm{n}}\right), \mathbf{n}=(\mathbf{1}, \ldots, \mathrm{N})
$$

Where $\mathbf{n}$ is a counter for the number of historical readings and $\mathbf{N}$ is its total number that may be taken for a month, season, or year. In "9", both $\mathbf{t}$ and $\Delta \mathbf{t}$ are fixed and $\mathbf{n}$ is changed until finishing all the studied historical readings, then moving to the next observation time $(\mathbf{t}+\Delta \mathbf{t})$. If $\Delta \boldsymbol{p}_{\boldsymbol{n}}$ is positive, it refers to power ramp-up $\left(\boldsymbol{\Delta} \boldsymbol{p}_{\boldsymbol{n}+}\right)$. Conversely, if $\boldsymbol{\Delta} \boldsymbol{p}_{\boldsymbol{n}}$ is negative, it refers to power ramp-down $\left(\boldsymbol{\Delta} \boldsymbol{p}_{\boldsymbol{n}_{-}}\right)$.

$$
\begin{array}{ll}
\text { If, } & \Delta p_{n}>0 \rightarrow \Delta p_{n+} \text { (Ramp-up), } \\
\text { and if, } & \Delta p_{n}<0 \rightarrow \Delta p_{n-} \text { (Ramp-down) }
\end{array}
$$

The average value of power ramps at an observation time $(\mathrm{t})$ is given by:

$$
\Delta p_{\text {avgt }}=\frac{1}{N} \sum_{n=1}^{N} \Delta p_{n}
$$

The positive average value indicates that the upward ramp is the most common at the observation time $\mathbf{t}$, whereas the negative average means that the ramp-down type is the most occurrence ramp type.

The standard deviation of power ramps at the observation time $\mathbf{t}$ is given by:

$$
\sigma_{t}=\sqrt{\frac{1}{N-1} \sum_{n=1}^{N}\left(\Delta \mathrm{p}_{n}-\Delta \mathrm{p}_{\mathrm{avgt}}\right)^{2}}
$$

The coefficient of variation of upward and downward power ramps within the selected time interval $(\Delta t)$ at an observation time $t$ is calculated as follows:

The average value of the upward and downward power ramps at the studied observation time $\mathbf{t}$ is given by:

$$
\begin{gathered}
\Delta p_{\text {avgt }+}=\frac{1}{N_{+}} \sum_{n_{+}=1}^{N_{+}} \Delta p_{n_{+}}, n_{+}=\left(1, \ldots, N_{+}\right) \\
\Delta p_{\text {avgt }-}=\frac{1}{N_{-}} \sum_{n_{-}=1}^{N_{-}} \Delta p_{n_{-}}, n_{-}=\left(1, \ldots, N_{-}\right)
\end{gathered}
$$

The standard deviation of upward and downward power ramps at the studied observation time $\mathbf{t}$ is given by:

$$
\begin{aligned}
& \sigma_{t+}=\sqrt{\frac{1}{N_{+}-1} \sum_{n_{+}=1}^{N_{+}}\left(\Delta p_{n_{+}}-\Delta p_{\text {avgt }+}\right)^{2}} \\
& \sigma_{t-}=\sqrt{\frac{1}{N_{-}-1} \sum_{n_{-}=1}^{N_{-}}\left(\Delta p_{n_{-}}-\Delta p_{\text {avgt- }}\right)^{2}}
\end{aligned}
$$

The coefficient of variation of upward power ramps at the observation time $\mathbf{t}$ is given by: 


$$
C V_{t+}=\frac{\sigma_{t+}}{\Delta p_{\text {avgt+ }}}
$$

The coefficient of variation of downward power ramps at the observation time $\mathbf{t}$ is given by:

$$
C V_{t-}=\frac{\sigma_{t-}}{\Delta p_{\text {avgt }-}}
$$

2. The coefficient of variation for daily power ramps (Horizontal analysis direction): It is the ratio between the standard deviation (his $\boldsymbol{\sigma}_{\boldsymbol{d}}$ ) and the average (his $\Delta \boldsymbol{p}_{\text {avgd }}$ ) of historical power ramps that occurred within the studied time interval $(\boldsymbol{\Delta t})$ over a certain number of days, which can be expressed as follows:

$$
C V_{d}=\frac{h i s \sigma_{d}}{\text { his } \Delta p_{\text {avgd }}}
$$

The daily historical readings of power are studied to measure the ramping behavior in certain weeks, months, seasons, or years within the studied time interval $\Delta t$. The power ramps time series in a studied day can be obtained by fixing $\Delta \mathbf{t}$ and changing $\mathbf{t}$ as follows:

$$
\begin{gathered}
\Delta p_{t}=P(t+\Delta t)-P(t), \mathrm{t}=(1, \ldots, h) \\
\Delta p_{t}>0 \rightarrow \Delta p_{n+} \text { Ramp-up } \\
\Delta p_{t}<0 \rightarrow \Delta p_{n-} \text { Ramp-down }
\end{gathered}
$$

The average value of power ramps ( $\Delta \mathbf{p}_{\text {avgd }}$ ) within the selected time interval $\Delta \mathbf{t}$ during the studied day and the standard deviation $\left(\boldsymbol{\sigma}_{\boldsymbol{d}}\right)$ is given by "(21)", "(22)":

$$
\begin{gathered}
\Delta p_{\text {avgd }}=\frac{1}{h} \sum_{t=1}^{h} \Delta p_{t} \\
\sigma_{d}=\sqrt{\frac{1}{h-1} \sum_{t=1}^{h}\left(\Delta p_{t}-\Delta p_{\text {avgd }}\right)^{2}}
\end{gathered}
$$

The average value and the standard deviation of power ramps over a certain number of days can be obtained as in "(23)":

$$
\begin{gathered}
h i s \Delta p_{\text {avgd }}=\frac{1}{d_{n}} \sum_{d_{1}}^{d_{n}} \Delta p_{\text {avgd }} \\
\text { his } \sigma_{d}=\mid \begin{array}{l}
d_{n} \\
d_{1}
\end{array} \sqrt{\frac{1}{h-1} \sum_{t=1}^{h}\left(\Delta p_{t}-h i s \Delta p_{\text {avgd }}\right)^{2}}
\end{gathered}
$$

For a week, month, and year, $d_{n}=7,30$, and 365 respectively.

The coefficient of variation of upward and downward power ramps is calculated as follows:

The average value and the standard deviation of upward and downward power ramps within the selected time interval $\Delta \mathbf{t}$ during the studied day is given by:

$$
\begin{gathered}
\Delta p_{\text {avgd }+}=\frac{1}{N_{+}} \sum_{n_{+}=1}^{N_{+}} \Delta p_{n_{+}}, \quad n_{+}=\left(1, \ldots, N_{+}\right) \\
\Delta p_{\text {avgd- }}=\frac{1}{N_{-}} \sum_{n_{-}=1}^{N_{-}} \Delta p_{n_{-}}, \quad n_{-}=\left(1, \ldots, N_{-}\right) \\
\sigma_{d+}=\sqrt{\frac{1}{N_{+}-1} \sum_{n_{+}=1}^{N_{+}}\left(\Delta p_{n_{+}}-\Delta p_{\text {avgd }}\right)^{2}} \\
\sigma_{d-}=\sqrt{\frac{1}{N_{-}-1} \sum_{n_{-}=1}^{N_{-}}\left(\Delta p_{n_{-}}-\Delta p_{\text {avgd }}\right)^{2}}
\end{gathered}
$$

The average value and the standard deviation of upward and downward power ramps over a certain number of days can be obtained as in "(28)":

$$
\begin{gathered}
\text { his } \Delta p_{\text {avgd }+/-}=\frac{1}{d_{n}} \sum_{d_{1}}^{d_{n}} \Delta p_{\text {avgd }+/-} \\
h i s \sigma_{d+/-}=\mid \begin{array}{l}
d_{n} \\
d_{1}
\end{array} \sqrt{\frac{1}{h-1} \sum_{t=1}^{h}\left(\Delta p_{n+/-}-h i s \Delta p_{\text {avgd }+/-}\right)^{2}}
\end{gathered}
$$

The coefficient of variation of upward and downward power ramps over a certain number of days is given by:

$$
C V_{d+/-}=\frac{\text { his } \sigma_{d+/-}}{\text { his } \Delta p_{\text {avgd+/- }}}
$$




\section{b. The Ramp Regularity Factor (RRF):}

It is defined as the ratio between the average $\left(\Delta \boldsymbol{p}_{\boldsymbol{a v g}}\right)$ and the maximum value $\left(\Delta \boldsymbol{p}_{\max }\right)$ of historical power ramps of the same type within the studied time interval $\Delta t$, which can be expressed as follows:

$$
R R F=\frac{\Delta p_{\text {avg }}}{\Delta p_{\max }}, \quad 0<R R F<1
$$

The values of RRF close to 1 show that the power changes are largely steady, indicating that the average and maximum ramps are about equal, and the average ramp value better represents the power ramps for that period and the system ramps are about equal. While the values of RRF close to zero show that the average value does not accurately describe the power ramps in that time interval, and unexpected high ramp occurrence is likely in that period, so the power system operators should take the necessary precautions.

1. The ramp regularity factor for an observation time $t\left(R \boldsymbol{R} \boldsymbol{F}_{t}\right)$ : It is the ratio between the average and the maximum value of historical power ramps of the same type within the studied time interval $(\Delta \mathbf{t})$ at the observation time $\mathbf{t}$, which can be expressed as follows:

$$
R R F_{t+/-}=\frac{\Delta p_{\text {avgt }+/-}}{\Delta p_{\text {maxt }+/-}}, \quad 0<R R F<1
$$

Where the maximum value of historical power ramps at the observation time $\mathbf{t}$ during the studied time interval $\Delta \mathbf{t}$ can be obtained from "(9)" as follows:

$$
\begin{aligned}
\Delta p_{\max t+} & =\max \Delta \mathrm{p}_{n} \\
\Delta p_{\max t-} & =\min \Delta \mathrm{p}_{n}
\end{aligned}
$$

2. The ramp regularity factor for daily power ramps $\left(\boldsymbol{R} R \boldsymbol{F}_{d}\right):$ It is the ratio between the average and the maximum value of historical power ramps of the same type that occurred within the studied time interval $(\boldsymbol{\Delta t})$ over a certain number of days, which can be expressed as follows:

$$
R R F_{d+/-}=\frac{h i s \Delta p_{\text {avgd }+/-}}{h i s \Delta p_{\operatorname{maxd}+/-}}, \quad 0<R R F<1
$$

The maximum value of upward and downward power ramps in a studied day within the studied time interval $\Delta \mathbf{t}$ can be obtained from "(20)" as follows:

$$
\begin{gathered}
\Delta p_{\max d+}=\max \Delta p_{t} \\
\Delta p_{\max d-}=\min \Delta p_{t}, \mathrm{t}=(1, \ldots, h)
\end{gathered}
$$

The maximum value of upward and downward power ramps over a certain number of days can be obtained as in " $(36,37)$ ":

$$
\begin{aligned}
& \text { his } \Delta p_{\text {maxd }+}=\left.\max \right|_{d_{1}} ^{d_{n}} \Delta p_{\text {maxd }}+ \\
& \text { his } \Delta p_{\text {maxd- }}=\left.\min \right|_{d_{1}} ^{d_{n}} \Delta p_{\text {maxd- }}
\end{aligned}
$$

\section{c.The ramp intensity factor (RIF):}

It is the ratio between the power ramp in a studied time interval to the maximum value of historical power ramps of the same type at that time interval. The RIF is a time-dependent factor that depends on the studied interval $\Delta \mathbf{t}$. The power system operator can use this factor to measure the intensity of the power ramp. The values of RIF close to zero represent very small ramps that can be neglected, while the values close to one refer to high power ramps. Therefore, this factor can be used in classifying the power ramps.

$$
R I F(t, \Delta \mathrm{t})=\frac{\Delta p(t)}{\Delta p_{\max }}, \quad 0 \leq R F \leq 1
$$

1. RIF for power ramps at an observation time t: It is the ratio between the power ramp that occurred within the studied time interval $\Delta \mathbf{t}$ at an observation time $\mathbf{t}$ and the maximum value of historical power ramps of the same type within the same time interval at that observation time. Therefore, the ramp intensity factor depends on the selected observation time $\mathbf{t}$ and the time interval $\Delta \mathbf{t}$. The metric can be used in classifying the power ramps at each observation time $\mathbf{t}$, where the classification of power ramps at an observation time $\mathbf{t}$ will depend on the local maximum value of historical power ramps at that observation time.

$$
R I F_{t+/-}=\frac{\Delta p_{t+/-}}{\Delta p_{\text {maxt }+/-}}, \quad 0 \leq R F \leq 1
$$

2. RIF for daily power ramps: It is the ratio between the power ramp that occurred in a studied day within the studied time interval $\Delta \mathbf{t}$ and the maximum value of historical power ramps of the same type for that time interval. Where the intensity of the power ramp at a certain time interval $\Delta \mathbf{t}$ is measured with respect to the global maximum value of historical power ramps at the same time interval. 


$$
R I F_{d+/-}=\frac{\Delta p_{t+/-}}{h i s \Delta p_{\text {maxd }+/-}}, \quad 0 \leq R F \leq 1
$$

This factor can also be used to measure the intensity of the local maximum value of power ramps at observation time $\mathbf{t}$ to the global maximum value of the same ramp type at the same time interval.

$$
R I F_{d+/-}=\frac{\Delta p_{\text {maxt }+/-}}{\text { his } \Delta p_{\text {maxd }+/-}}, \quad 0 \leq R F \leq 1
$$

\section{d. The maximum ramp ratio (MRR):}

It is defined as the ratio between the maximum downward value to the maximum upward value of historical power ramps within the studied time interval $\Delta \mathbf{t}$, which can be expressed as follows:

$$
\operatorname{MRR}=\frac{\Delta p_{\max }}{\Delta p_{\max }}
$$

From the power system operators' point of view, the downward ramps in the wind or solar power are more difficult to be managed than upward ramps, whereas the upward ramps in load or net-load are more difficult to be managed than downward, therefore the MRR compares their maximum values at the studied time interval. The MRR can be used to calculate the followings:

1. MRR at an observation time $t$ : It is defined as the ratio between the maximum downward value to the maximum upward value of historical power ramps within the studied time interval $\Delta \mathbf{t}$ at an observation time $\mathbf{t}$.

$$
M R R_{t}=\frac{\Delta p_{\text {maxt }-}}{\Delta p_{\max t+}}
$$

2. MRR for daily power ramps: It is defined as the ratio between the maximum downward value to the maximum upward value of historical power ramps within the studied time interval $\Delta \mathbf{t}$.

$$
M R R_{d}=\frac{\text { his } \Delta p_{\operatorname{maxd}-}}{\text { his } \Delta p_{\operatorname{maxd}+}}
$$

\subsection{CASE STUDY}

Nuclear power in Belgium, which accounts for $50 \%$ of the total electricity generated, is planned to be phased out over the next five years. As a result, Belgium's share of RG is expected to double in 2030 compared to that in 2017, where RG in 2017 represented around $17 \%$ of the total electricity consumption. Therefore, wind capacity is increasing continuously. Using the analytical methodologies described above, the ramp metrics are applied to the output power of Belgium's aggregated wind farms (onshore and offshore) recorded every $15 \mathrm{~min}$ in 2017 and 2018 [71]. The maximum installed wind capacity in 2017 was 2621.924 MW, and the average installed wind capacity throughout the year was 2439.074 MW. Whereas in 2018, the maximum installed wind capacity was $3157.185 \mathrm{MW}$, and the average installed wind capacity throughout the year was 2922.08 MW. The variations in wind power are calculated within the time interval of $15 \mathrm{~min}$.

\section{Results and Discussion}

\subsection{Vertical analysis results and discussion}

Table 2 summarizes the range and the average value of ramp metrics for upward and downward power ramps that occurred within a time interval of 15 min across all observation times in 2017 and 2018.

In Figure 6, the comparison between the coefficients of variation of upward power ramps within a time interval of 15 min at each observation time in 2017 and 2018 is shown. The CV values of the two years are approximately equal for most observation times, the CV values in the period from 5:00 AM to 9:00 AM and from 16:15 to 20:45 are lower than those in the other periods. The average values of CV for the two years are approximately equal and greater than one, as the average values of CV in 2017 and 2018 are equal to 1.15 and 1.16 respectively. The CV values range from 0.93 to 1.7 in 2017 , and range in 2018 from 0.88 to 1.85 .

In Figure 7, the comparison between the coefficients of variation of downward power ramps within a time interval of 15 min at each observation time in 2017 and 2018 is shown. The CV values of the two years are approximately equal for most observation times. The average values of $\mathrm{CV}$ in the two years are approximately equal and more than one, as the average values of CV in 2017 and 2018 are equal to 1.18 and 1.14 respectively. The CV values range from 0.95 to 2 in 2017, and range in 2018 from 0.88 to 1.5. Therefore for upward and downward power ramps, the range and the average of $\mathrm{CV}$ values in the two years are approximately equal, thus the $\mathrm{CV}$ can describe accurately the variation of both types of power ramps in wind generation in the two years. For most observation times, the $\mathrm{CV}$ values are more than one, indicating that the average value does not describe correctly the power ramps in these observation times. 


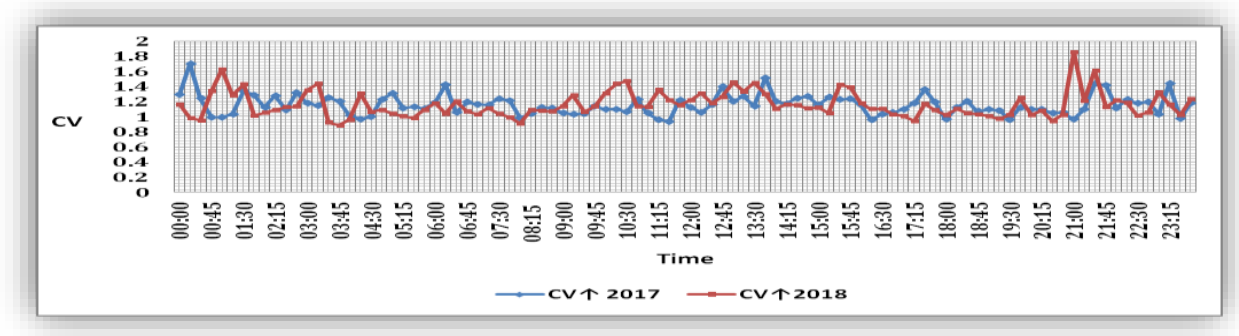

Figure 6. Comparison of the coefficients of variation of upward power ramps within a time interval of 15 min at each observation time in 2017 and 2018

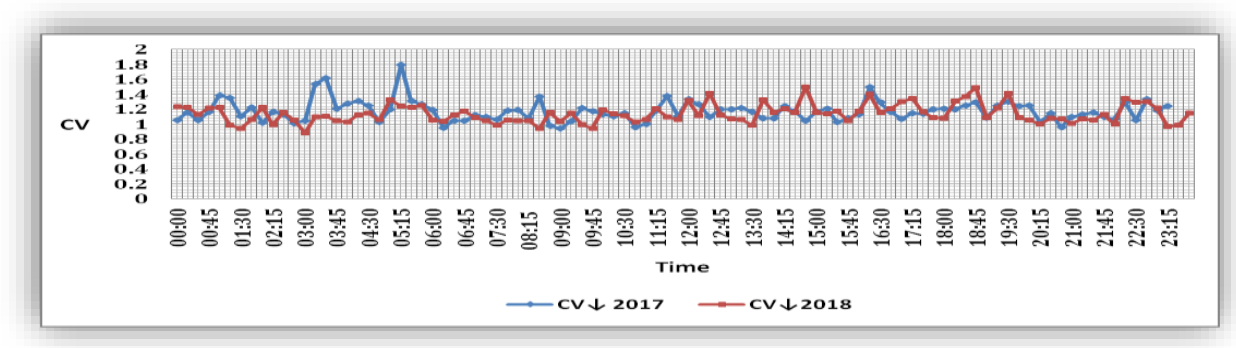

Figure 7. Comparison of the coefficients of variation of downward power ramps within a time interval of 15 min at each observation time in 2017 and 2018

In Figure 8, the comparison between the ramp regularity factors of upward power ramps within a time interval of $15 \mathrm{~min}$ at each observation time in 2017 and 2018 is shown. The range and the average value of RRF in the two years are equal, as the values of RRF range from 0.06 to 0.26 in 2017, and range in 2018 from 0.04 to 0.25 . While the average value of RRF is equal to 0.14 in the two years.

In Figure 9, the comparison between the ramp regularity factors of downward power ramps within a time interval of 15 min at each observation time in 2017 and 2018 is shown. For most observation times, the values of RRFs in the two years are close to each other, so the range and the average value of RRFs in the two years are equal, as the values of RRF range from 0.04 to 0.23 in 2017, while in 2018 range from 0.07 to 0.26. The average values of RRF in 2017 and 2018 are equal to 0.13 and 0.14 respectively. Therefore, for upward and downward power ramps, the range and the average value of RRFs in the two years are equal, so the RRF describes accurately both types of power ramps in wind generation in the two years. The low values of RRF which are close to zero show the high occurrence probability of unexpected high power ramps of both types. Besides, the high variability in wind generation so the average value of power ramps does not represent the actual variation.

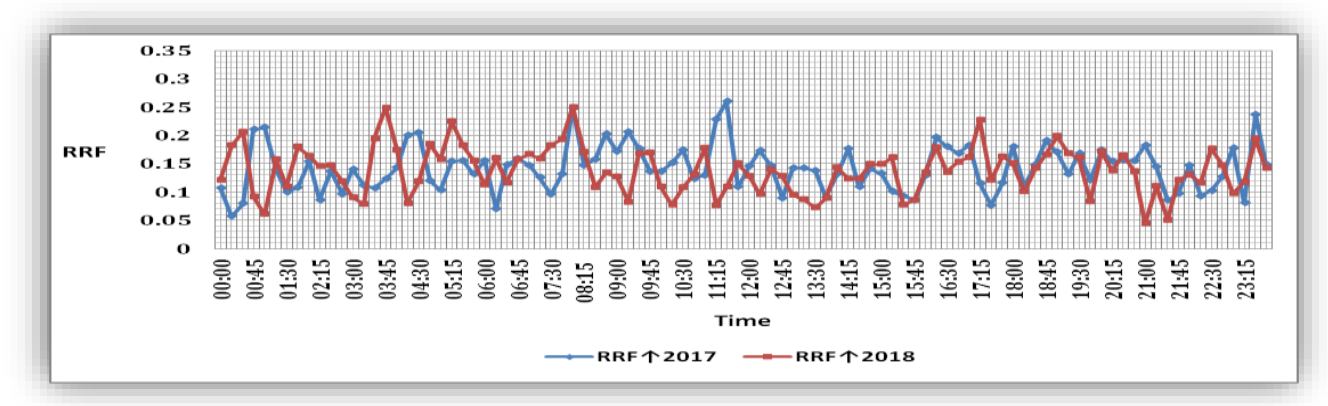

Figure 8. Comparison of the ramp regularity factors of upward power ramps within a time interval of $15 \mathrm{~min}$ at each observation time in 2017 and 2018 


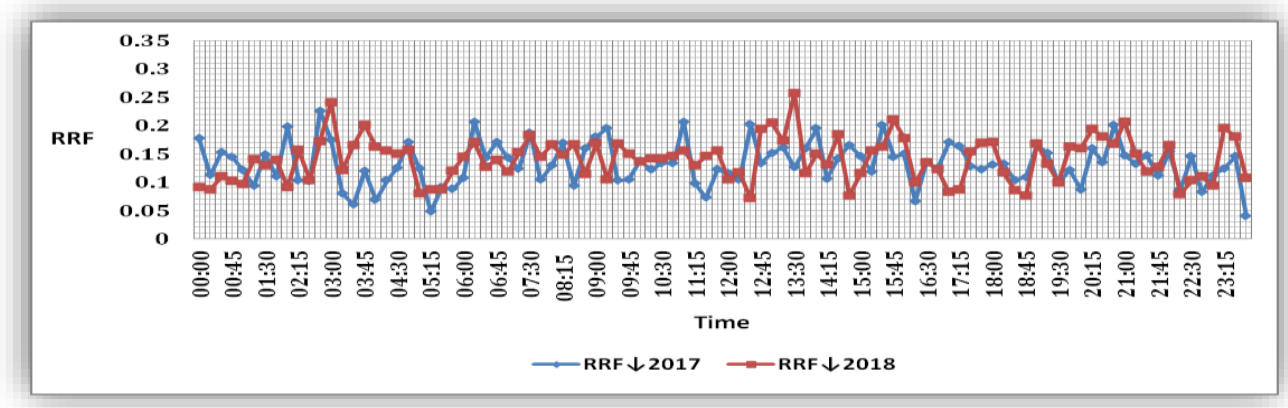

Figure 9. Comparison of the ramp regularity factors of downward power ramps within a time interval of 15 min at each observation time in 2017 and 2018

In Figures 10, 11, the RIFs illustrate the intensity difference of the local maximum value of power ramps of both types at each observation time. In Figure 10, the comparison between the RIFs of maximum upward power ramps within a time interval of $15 \mathrm{~min}$ at each observation time in 2017 and 2018 is shown. The ranges of the RIFs in the two years are approximately equal, as the RIFs in 2017 range from 0.17 to 1 , while in 2018 range from 0.14 to 1 . The average value of RIFs in 2018 is to some extent less than that in 2017 , as the average value of RIFs in 2018 is 0.3 compared to 0.42 in 2017. In Figure 11, the comparison between the RIFs of maximum downward power ramps within a time interval of $15 \mathrm{~min}$ at each observation time in 2017 and 2018 is shown. The values of RIFs in 2017 range from 0.14 to 1 , while in 2018 range from 0.23 to 1 . The average value of RIFs in 2018 is higher than in 2017; the average value of RIFs in 2018 is 0.46 , compared to 0.3 in 2017.

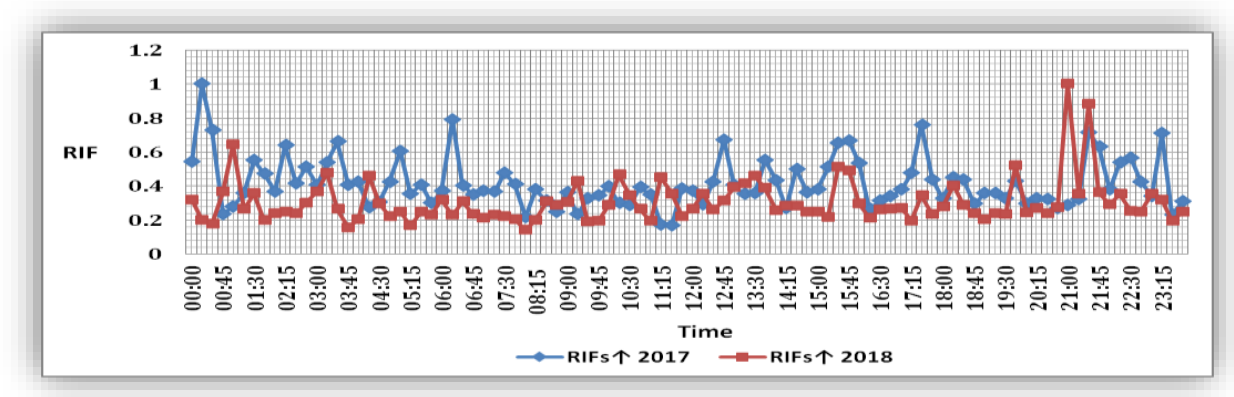

Figure 10. Comparison of the RIFs of maximum upward power ramps within a time interval of 15 min at each observation time in 2017 and 2018

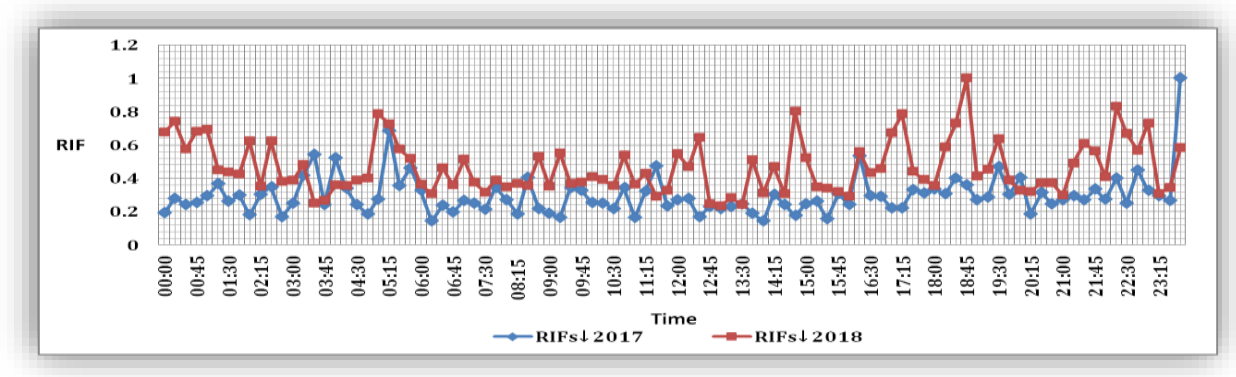

Figure 11. Comparison of the RIFs of maximum downward power ramps within a time interval of 15 min at each observation time in 2017 and 2018

In Figure 12, the comparison between the MRR of power ramps within a time interval of 15 min at each observation time in 2017 and 2018 is shown. For most observation times, the values of MRR in the two years are close to each other, but the range is different, as the values of MRR in 2017 range from 0.27 to 4.73, while in 2018 range from 0.18 to 2.7. However, the average values of MRR in the two years are approximately equal and greater than 1, with 1.07 in 2018 and 1.19 in 2017, indicating that the maximum values of downward power ramps are to some extent greater than that of upward power ramps. 


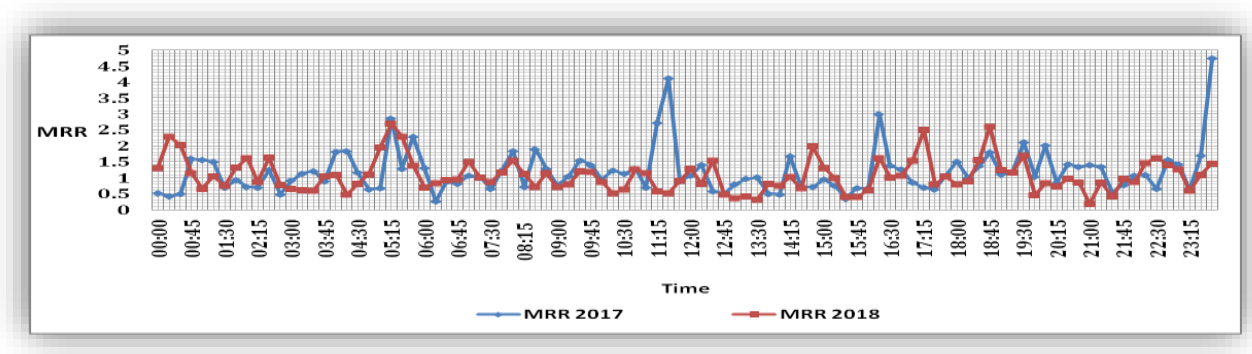

Figure 12. Comparison of the MRR of power ramps within a time interval of $15 \mathrm{~min}$ at each observation time in 2017 and 2018

Table 2. The range and the average value of ramp metrics for upward and downward power ramps that occurred within a time interval of 15 min across all observation times in 2017 and 2018

\begin{tabular}{ccccccc}
\hline Ramp & \multicolumn{4}{c}{ UPWARD POWER RAMPS } \\
\cline { 2 - 6 } & \multicolumn{3}{c}{$\mathbf{2 0 1 7}$} & \multicolumn{4}{c}{$\mathbf{2 0 1 8}$} \\
\cline { 2 - 6 } & \multicolumn{2}{c}{ Range } & Avg. & \multicolumn{2}{c}{ Range } & Avg. \\
\cline { 2 - 6 } \cline { 4 - 6 } & From & To & $\mathbf{2 0 1 7}$ & From & To & $\mathbf{2 0 1 8}$ \\
\hline CV & 0.93 & 1.7 & 1.15 & 0.88 & 1.85 & 1.16 \\
RRF & 0.06 & 0.26 & 0.14 & 0.04 & 0.25 & 0.14 \\
RIF & 0.17 & 1 & 0.42 & 0.14 & 1 & 0.3 \\
\hline \multicolumn{4}{c}{ DOWNWARD POWER RAMPS } \\
\hline CV & 0.95 & 2 & 1.18 & 0.88 & 1.5 & 1.14 \\
RRF & 0.04 & 0.23 & 0.13 & 0.07 & 0.26 & 0.14 \\
RIF & 0.14 & 1 & 0.3 & 0.23 & 1 & 0.46 \\
\hline MRR & 0.27 & 4.73 & 1.19 & 0.18 & 2.7 & 1.07 \\
\hline
\end{tabular}

\subsection{Horizontal analysis results and discussion}

Table 3 summarizes the range and the average value of ramp metrics for upward and downward power ramps that occurred within a time interval of 15 min across all months in 2017 and 2018 .

In Figure 13, the comparison between the coefficients of variation of upward power ramps within a time interval of 15 min for each month in 2017 and 2018 is shown. The CV values of the two years are approximately equal for all months except July. The average values of CV in the two years are equal and more than one, as the average values of $\mathrm{CV}$ in the two years are equal to 1.16.

In Figure 14, the comparison between the coefficients of variation of downward power ramps within a time interval of 15 min for each month in 2017 and 2018 is shown. For most months, the CV values of the two years are approximately equal. The average values of $\mathrm{CV}$ in the two years are approximately equal and more than one, as the average values of CV in 2017 and 2018 are equal to 1.2 and 1.13 respectively. The range of $\mathrm{CV}$ in the two years is equal, as the values of $\mathrm{CV}$ range from 0.99 to 1.4 in the two years. Therefore for upward and downward power ramps, the range and the average of CV values in the two years are equal, thus the CV can describe accurately the variation of both types of power ramps in wind generation in the two years. For most months, the $\mathrm{CV}$ values are more than one, indicating that the average value does not describe correctly the power ramps in these months.

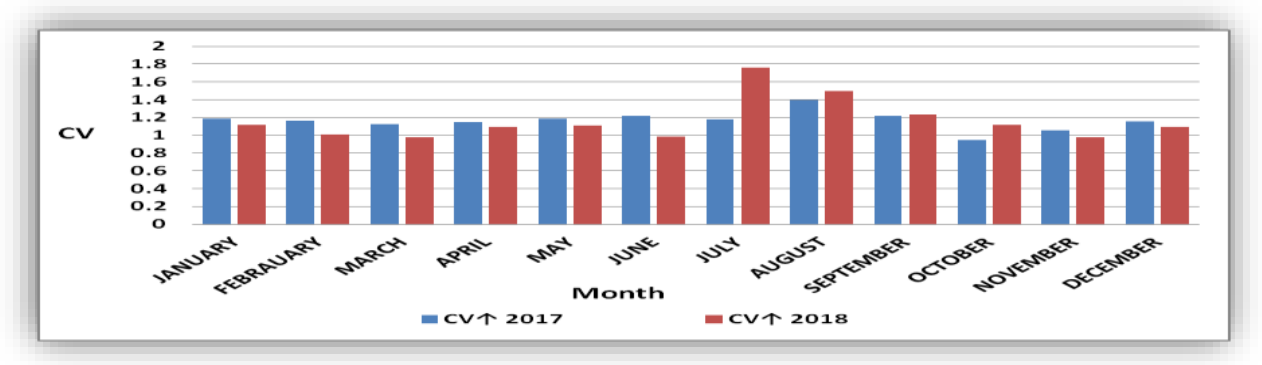

Figure 13. Comparison of the coefficients of variation of upward power ramps within a time interval of 15 min for each month in 2017 and 2018 


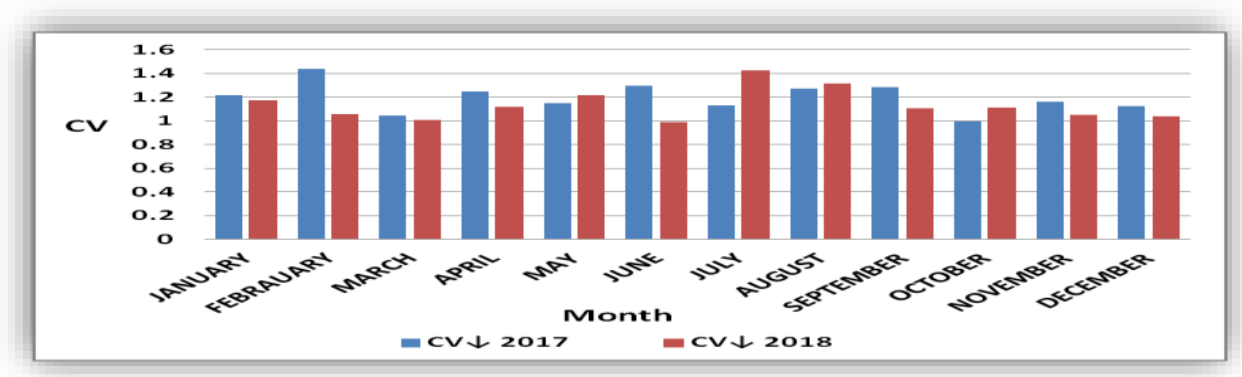

Figure 14. Comparison of the coefficients of variation of downward power ramps within a time interval of 15 min for each month in 2017 and 2018

In Figure 15, the comparison between the ramp regularity factors of upward power ramps within a time interval of 15 min for each month in 2017 and 2018 is shown. The range and the average of RRF in the two years are equal, the values of RRF range from 0.06 to 0.14 with an average value of 0.09 in 2017 . While in 2018 , they range from 0.03 to 0.15 , with an average value of 0.1 . In Figure 16, the comparison between the ramp regularity factors of downward power ramps within a time interval of 15 min for each month in 2017 and 2018 is shown. The range and the average of RRF in the two years are equal, the values of RRF range from 0.03 to 0.12 with an average value of 0.08 in 2017 . While in 2018 , they range from 0.06 to 0.13 with an average value of 0.09. Therefore, for upward and downward power ramps, the range and the average of RRFs in the two years are equal, so the RRF describes accurately both types of power ramps in wind generation in the two years. The low values of the ramp regularity factor which are close to zero show the high occurrence probability of unexpected high power ramps of both types. In addition, the high variability in wind generation so the average value of power ramps does not represent the actual variation.

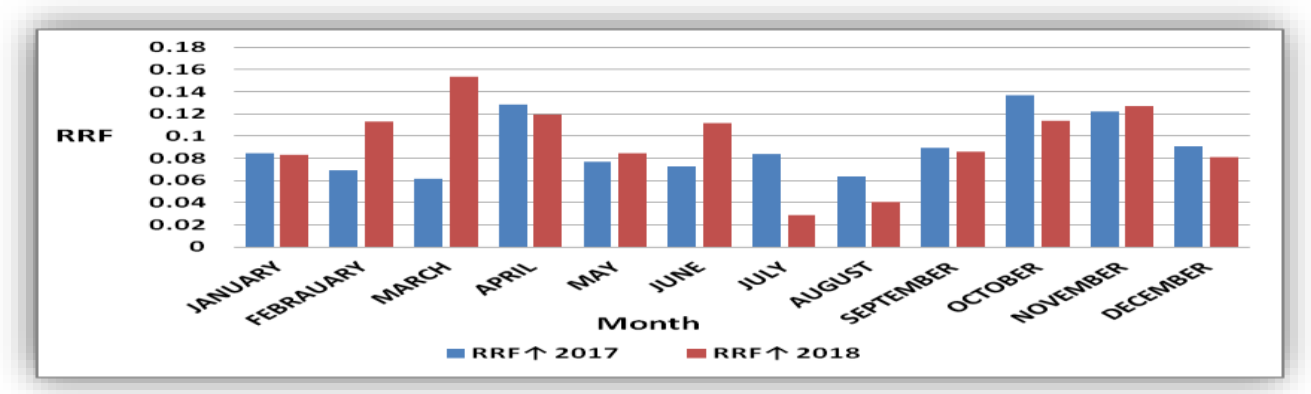

Figure 15. Comparison of the ramp regularity factors of upward power ramps within a time interval of $15 \mathrm{~min}$ for each month in 2017 and 2018

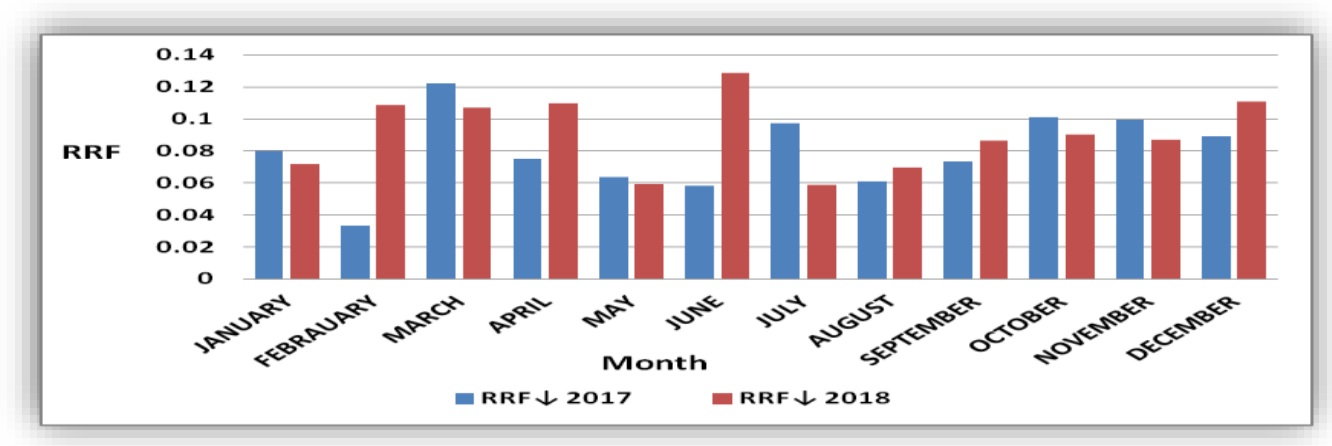

Figure 16. Comparison of the ramp regularity factors of downward power ramps within a time interval of 15 min for each month in 2017 and 2018

In Figures 17, 18, the RIFs illustrate the intensity difference of the local value of maximum power ramps of both types for each month. In Figure 17, the comparison between RIFs of maximum upward power ramps within a time interval of 15 min for each month in 2017 and 2018 is shown. The RIFs in 2017 range from 0.38 to 1 , while in 2018 range from 0.26 to 1 . The average value of RIFs in 2018 is to some extent less 
than that in 2017, with an average value of 0.47 compared to 0.65 in 2017 . In Figure 18 , the comparison between RIFs of maximum downward power ramps within a time interval of 15 min for each month in 2017 and 2018 is shown. The range of RIFs in the two years is approximately equal, as RIFs in 2017 range from 0.34 to 1 , while in 2018 range from 0.37 to 1 . The average value of RIFs in 2018 is more than that in 2017, as the average value of RIFs in 2018 is 0.69 while in 2017 it is 0.5 .

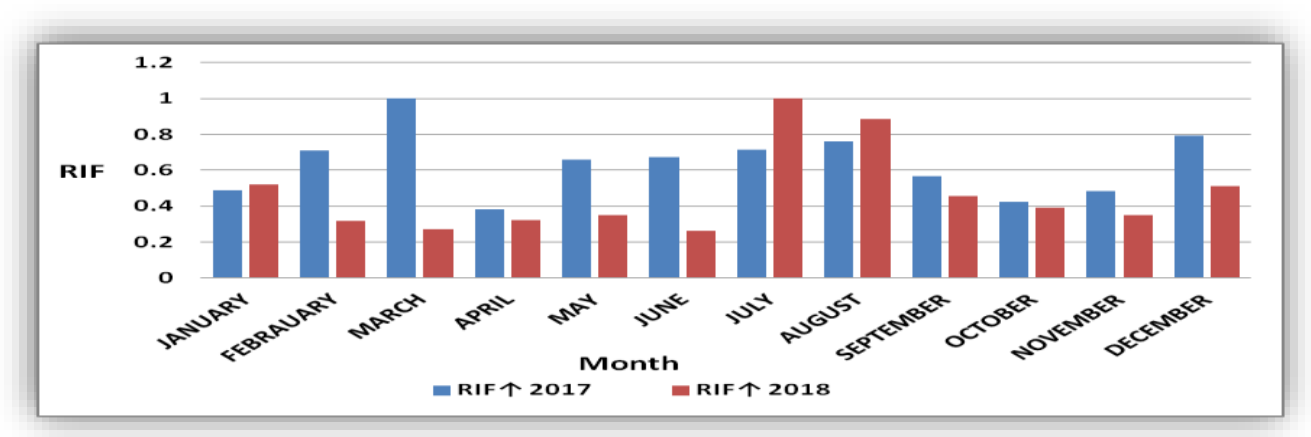

Figure 17. Comparison of the RIFs of upward power ramps within a time interval of 15 min for each month in 2017 and 2018

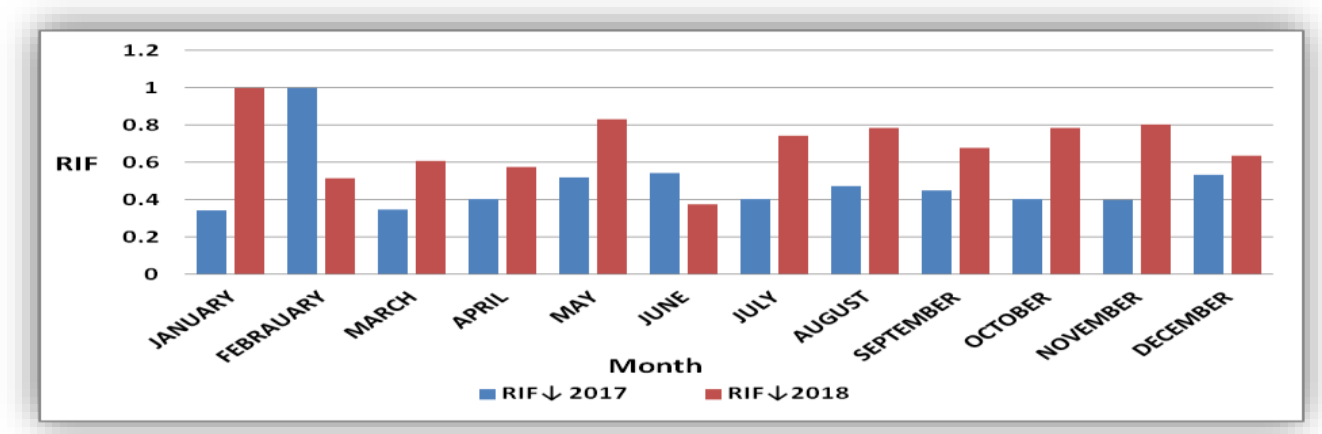

Figure 18. Comparison of the RIFs of downward power ramps within a time interval of 15 min for each month in 2017 and 2018

In Figure 19, the comparison between MRR of power ramps within a time interval of 15 min for each month in 2017 and 2018 is shown. The range and the average values of MMR in the two years are approximately equal, as the MRR in 2017 ranges from 0.51 to 2.08, and in 2018 ranges from 0.46 to 1.46. While the average values of MRR in 2017 and 2018 are greater than one, recording 1.17 and 1.03, respectively, this indicates that the maximum values of downward power ramps are to some extent more than those of upward power ramps.

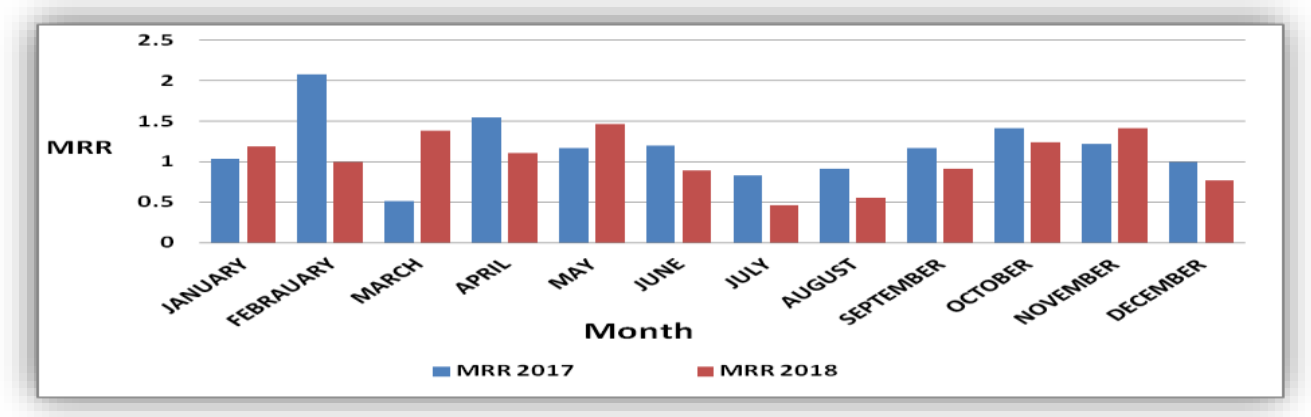

Figure 19. Comparison of MRR of power ramps within a time interval of 15 min for each month in 2017 and 2018 
Table 3. The range and the average value of ramp metrics for upward and downward power ramps that occurred within a time interval of 15 min across all months in 2017 and 2018

\begin{tabular}{|c|c|c|c|c|c|c|}
\hline \multirow{4}{*}{$\begin{array}{l}\text { Ramp } \\
\text { Metrics }\end{array}$} & \multicolumn{6}{|c|}{ UPWARD POWER RAMPS } \\
\hline & \multicolumn{3}{|c|}{2017} & \multicolumn{3}{|c|}{2018} \\
\hline & \multicolumn{2}{|c|}{ Range } & \multirow{2}{*}{$\begin{array}{l}\text { Avg. } \\
2107\end{array}$} & \multicolumn{2}{|c|}{ Range } & \multirow{2}{*}{$\begin{array}{l}\text { Avg. } \\
2018\end{array}$} \\
\hline & From & To & & From & To & \\
\hline $\mathbf{C V}$ & 0.94 & 1.4 & 1.16 & 0.97 & 1.76 & 1.16 \\
\hline RRF & 0.06 & 0.14 & 0.09 & 0.03 & 0.15 & 0.1 \\
\hline \multirow[t]{2}{*}{ RIF } & 0.38 & 1 & 0.65 & 0.26 & 1 & 0.47 \\
\hline & \multicolumn{6}{|c|}{ DOWNWARD POWER RAMPS } \\
\hline CV & 0.99 & 1.44 & 1.2 & 0.99 & 1.42 & 1.13 \\
\hline RRF & 0.03 & 0.12 & 0.08 & 0.06 & 0.13 & 0.09 \\
\hline RIF & 0.34 & 1 & 0.5 & 0.37 & 1 & 0.69 \\
\hline MRR & 0.51 & 2.08 & 1.17 & 0.46 & 1.46 & 1.03 \\
\hline
\end{tabular}

\section{CONCLUSION}

The increasing penetration level of VRG has led to more netload fluctuations and ramp events, so it is desirable for the power system operators to gain a deeper understanding of the aggregated ramping behavior scale, as well as the periods where the collective ramp events are most likely to occur. The paper has presented different definitions for solar, wind, load, and net-load ramp event, in which the percentage threshold of ramp event magnitude ranges from $1 \% \boldsymbol{P}_{\boldsymbol{R}}$ to $75 \% \boldsymbol{P}_{\boldsymbol{R}}$ and the threshold of ramp event duration extends from $5 \mathrm{~min}$ to $6 \mathrm{~h}$. This great distinction in defining the ramp events is due to the difference between power systems utilities in both characteristics and flexibility available to meet these ramp events.

The relation between the occurrence of ramp events and meteorological processes has been discussed to understand the meteorological phenomena that produce large ramp events. However, relating ramp events to meteorological phenomena is extremely a case-dependent problem. Moreover, a high percentage of ramp events could not be explained. The paper introduced new ramp metrics that can describe the power ramping features whether they are in RG, load, or net-load. Therefore, these metrics can be applied to any power system. The time resolution used for quantifying the variability is chosen by the power system operators from one second to several hours depending on the stage of operation (regulation, load following, and unit commitment). These metrics are based on extracting information from the power system databases to be utilized in the power system operation. The new metrics are ramp regularity factor (RRF), ramp intensity factor (RIF), and maximum ramp ratio (MRR). In addition, the coefficient of variation $(\mathbf{C V})$, which was proposed to measure the degree of variability in relation to the mean of the data set, has been re-used to describe ramping behavior.

The value of RRF is from 0 to 1 . A high RRF means that the power ramps are relatively constant and the average value of power ramps properly represents the system ramps for the studied period, while a low RRF shows that an unexpected high ramp is likely to occur during that period, and to service this ramp, additional capacity is sitting idle for long periods, which increases costs. RIF is a time-dependent factor that can be used to measure the intensity of the ramp event. The RIF takes values from 0 to 1 , where values close to zero represent very small ramps that can be neglected, while values close to 1 refer to high power ramps. Therefore, this factor can be used in classifying the power ramps. MRR measures the ratio between the maximum downward value of historical power ramps within the studied time interval $\Delta \mathbf{t}$ to that of upward power ramps. From the power system operators' point of view, the downward ramps in the wind or solar power are more difficult to be managed than upward ramps, whereas the upward ramps in load or net-load are more difficult to be managed than downward. Therefore, the MRR compares their maximum values at the studied time interval. CV shows the scale of variability in relation to the average value of power ramps. If the value of CV within a studied time interval is less than one, the average value well describes the power ramps in that time interval. While if the value of $\mathbf{C V}$ is more than one, the average value does not describe correctly the power ramps in that time interval, indicating a high level of variation in ramp readings. The $\mathbf{C V}$ can be used also in comparing the variability of different power systems.

The new ramp metrics have been applied to the output power of Belgium's aggregated wind farms in 2017 and 2018; the obtained results demonstrate that the two years are showing nearly the same ramping behavior, although the average installed wind capacity has been increased.

\section{REFERENCES}

[1] I. Renewable and E. Agency, 'Renewable capacity statistics 2020', International Renewable Energy Agency (IRENA), Abu Dhabi, 2020. [Online]. Available: www.irena.org/Publications. 
[2] M. S. Eltohamy, M. S. A. Moteleb, H. Talaat, S. F. Mekhemar, and W. Omran, 'Overview of Power System Flexibility Options with Increasing Variable Renewable Generations', in 6th International Conference on Advanced Control Circuits and Systems (ACCS) \& 2019 5th International Conference on New Paradigms in Electronics \& Information Technology (PEIT), 2019, pp. 280-292, doi: DOI: 10.1109/ACCSPEIT48329.2019.9062836.

[3] N. Pearre, K. Adye, and L. Swan, 'Proportioning wind, solar, and in-stream tidal electricity generating capacity to co-optimize multiple grid integration metrics', Appl. Energy, vol. 242, no. March, pp. 69-77, 2019, doi: 10.1016/j.apenergy.2019.03.073.

[4] L. C and N. L., 'Variability Comparison of Large-Scale Photovoltaic Systems Across Diverse Geographic Climates', Eu-Pvsec, no. January 2010, pp. 4876-4882, 2010, doi: 10.4229/25thEUPVSEC2010-5AO.8.5.

[5] J. S. Stein, C. W. Hansen, and M. J. Reno, 'The variability index: A new and novel metric for quantifying irradiance and PV output variability', World Renew. Energy Forum, WREF 2012, Incl. World Renew. Energy Congr. XII Color. Renew. Energy Soc. Annu. Conf., vol. 4, pp. 2764-2770, 2012.

[6] Y. Cui, F. Bai, Y. Liu, and D. Smith, 'Statistical Characterization of Solar Irradiance Variability and Its Effect on Step Voltage Regulators', 2019 IEEE PES Innov. Smart Grid Technol. Asia, ISGT 2019, no. 1, pp. 3245-3250, 2019, doi: 10.1109/ISGT-Asia.2019.8881275.

[7] J. Huang and R. J. Davy, 'Predicting intra-hour variability of solar irradiance using hourly local weather forecasts', Sol. Energy, vol. 139, pp. 633-639, 2016, doi: 10.1016/j.solener.2016.10.036.

[8] G. M. Lohmann, 'Irradiance Variability Quantification and Small-Scale Averaging in Space and Time : A Short Review', Atmosphere (Basel)., vol. 9, no. 264, p. 22, 2018, doi: 10.3390/atmos9070264.

[9] A. K. Das, 'Quantifying photovoltaic power variability using Lorenz curve', J. Renew. Sustain. Energy, vol. 033124, no. 6, pp. 0-9, 2014, doi: 10.1063/1.4881655.

[10] T. E. Hoff and R. Perez, 'Quantifying PV power Output Variability', Sol. Energy, vol. 84, no. 10, pp. 1782-1793, 2010, doi: 10.1016/j.solener.2010.07.003.

[11] K. Keeratimahat, A. G. Bruce, and I. Macgill, 'Short term variability of utility-scale PV in the Australian National Electricity Market’, Asia-Pacific Sol. Res. Conf., 2017.

[12] B. Huang, I. S. Member, V. Krishnan, I. Member, B. Hodge, and I. S. Member, 'Analyzing the Impacts of Variable Renewable Resources on California Net-Load Ramp Events', no. August, pp. 1-5, 2018.

[13] A. A. Thatte and L. Xie, 'A metric and market construct of inter-temporal flexibility in time-coupled economic dispatch', IEEE Trans. Power Syst., vol. 31, no. 5, pp. 3437-3446, 2016, doi: 10.1109/TPWRS.2015.2495118.

[14] A. Dybvad, 'Wind Power Forecasting Physical Modelling', Norwegian University of Life Sciences, 2019.

[15] S. Goodarzi, H. N. Perera, and D. Bunn, 'The impact of renewable energy forecast errors on imbalance volumes and electricity spot prices', Energy Policy, vol. 134, no. October 2018, p. 110827, 2019, doi: 10.1016/j.enpol.2019.06.035.

[16] A. J. Deppe, W. A. Gallus, and E. S. Takle, 'A WRF Ensemble for Improved Wind Speed Forecasts at Turbine Height', Weather Forecast., vol. 28, pp. 212-228, 2013, doi: 10.1175/WAF-D-11-00112.1.

[17] C. Otero-Casal, P. Patlakas, M. A. Prosper, G. Galanis, and G. Miguez-Macho, 'Development of a HighResolution Wind Forecast System Based on the WRF Model and a Hybrid', Energies, vol. 12, no. 3050, pp. 1-19, 2019, doi: 10.3390/en12163050.

[18] I. Würth et al., 'Minute-scale forecasting of wind power-results from the collaborative workshop of IEA Wind task 32 and 36', Energies, vol. 12, no. 4, 2019, doi: 10.3390/en12040712.

[19] C. Kamath, 'Understanding Wind Ramp Events Through Analysis of Historical Data', in IEEE PES Transmission and Distribution Conference and Expo, April 20-22, 2010, pp. 1-6.

[20] G. Ren, J. Wan, J. Liu, D. Yu, and L. Söder, 'Analysis of wind power intermittency based on historical wind power data', Energy, vol. 150, pp. 482-492, 2018, doi: 10.1016/j.energy.2018.02.142.

[21] G. Ren, J. Liu, J. Wan, Y. Guo, and D. Yu, 'Overview of wind power intermittency: Impacts , measurements , and mitigation solutions', Appl. Energy, vol. 204, pp. 47-65, 2017, doi: 10.1016/j.apenergy.2017.06.098.

[22] S. Watson, 'Quantifying the variability of wind energy', WIREs Energy Environ., vol. 3, pp. 330-342, 2014, doi: 10.1002/wene.95.

[23] R. J. Davy, M. J. Woods, C. J. Russell, and P. A. Coppin, 'Statistical Downscaling of Wind Variability from Meteorological Fields', Boundary-Layer Meteorol, no. 135, pp. 161-175, 2010, doi: 10.1007/s10546-009-94627.

[24] A. Upadhyay, B. Hu, J. Li, and L. Wu, 'A chance-constrained wind range quantification approach to robust scuc by determining dynamic uncertainty intervals', CSEE J. Power Energy Syst., vol. 2, no. 1, pp. 54-64, 2016, doi: 10.17775/cseejpes.2016.00009.

[25] P. Doody and S. Santoso, 'A comparative metric to quantify the variability of wind power', 2009 IEEE Power Energy Soc. Gen. Meet. PES '09, no. 1, pp. 1-6, 2009, doi: 10.1109/PES.2009.5275581.

[26] T. Boutsika and S. Santoso, 'Quantifying Short-term Wind Power Variability', pp. 1-7, 2011.

[27] W. Katzenstein and J. Apt, 'The cost of wind power variability', Energy Policy, vol. 51, pp. 233-243, 2012, doi: 10.1016/j.enpol.2012.07.032.

[28] J. P. Deane, G. Drayton, and B. P. Ó. Gallachóir, 'The impact of sub-hourly modelling in power systems with significant levels of renewable generation q', Appl. Energy, vol. 113, pp. 152-158, 2014, doi: 10.1016/j.apenergy.2013.07.027.

[29] J. Kiviluoma, H. Holttinen, D. Weir, R. Scharff, and L. Söder, 'Variability in large-scale wind power generation', Wind Energy, vol. 18, no. 11, pp. 1649-1665, 2015, doi: 10.1002/we. 
[30] D. A. Halamay and T. K. A. Brekken, 'A Methodology for Quantifying Variability of Renewable Energy Sources by Reserve Requirement Calculation', pp. 666-673, 2010.

[31] S. Han et al., 'Quantitative evaluation method for the complementarity of wind - solar - hydro power and optimization of wind - solar ratio', Appl. Energy, vol. 236, no. November 2018, pp. 973-984, 2019, doi: 10.1016/j.apenergy.2018.12.059.

[32] M. S. Eltohamy, M. S. A. Moteleb, H. Talaat, S. F. Mekhemar, and W. Omran, 'Power System Flexibility Metrics Evaluation and Power Ramping Analysis for High Variable Renewable Generation Shares', EAI Endorsed Trans. Energy Web, vol. 8, no. 31, pp. 1-23, 2020, doi: 10.4108/eai.13-7-2018.165282.

[33] M. S. Eltohamy, M. S. A. Moteleb, H. Talaat, S. F. Mekhemar, and W. Omran, 'Analyzing Wind Power Ramps for High Penetration of Variable Renewable Generation', in 2019 21st International Middle East Power Systems Conference (MEPCON), 2019, pp. 768-775, doi: 10.1109/MEPCON47431.2019.9007951.

[34] M. S. Eltohamy, M. S. A. Moteleb, H. Talaat, S. F. Mekhemar, and W. Omran, 'Wind Power Ramps Analysis for High Shares of Variable Renewable Generation in Power Systems', Indones. J. Electr. Eng. Informatics, vol. 8, no. 2, pp. 256-272, 2020, doi: 10.11591/ijeei.v8i2.1984.

[35] T. Ouyang, X. Zha, and L. Qin, 'A Survey of Wind Power Ramp Forecasting', Energy Power Eng., vol. 05, no. 04, pp. 368-372, 2013, doi: 10.4236/epe.2013.54B071.

[36] B. Greaves, J. Collins, J. Parkes, and A. Tindal, 'Temporal Forecast Uncertainty for Ramp Events', Wind Eng., vol. 33, no. 4, pp. 309-319, 2009, doi: 10.1260/030952409789685681.

[37] S. Kudo, 'Characterising collective ramp events of distributed photovoltaic systems in Brisbane, Australia', no. October, 2015, [Online]. Available: http://www.nickengerer.org/s/u4672958_Shaw_Kudo_thesis_2015-3cuk.pdf.

[38] A. Florita, B. M. Hodge, and K. Orwig, 'Identifying wind and solar ramping events', IEEE Green Technol. Conf., no. January, pp. 147-152, 2013, doi: 10.1109/GreenTech.2013.30.

[39] C. W. Potter, E. Grimit, and B. Nijssen, 'Potential benefits of a dedicated probabilistic rapid ramp event forecast tool', 2009 IEEE/PES Power Syst. Conf. Expo. PSCE 2009, pp. 1-5, 2009, doi: 10.1109/PSCE.2009.4840109.

[40] J. V. Zack, J.W., S. Young, J. Nocera, J. Aymami, 'Development and Testing of an Innovative Short-Term Large Wind Ramp Forecasting System', in Proceedings of the Annual Conference - Canadian Wind Energy Association, 2011, pp. 885-900.

[41] N. Cutler, M. Kay, K. Jacka, and T. S. Nielsen, 'Detecting, categorizing and forecasting large ramps in wind farm power output using meteorological observations and WPPT', Wind Energy, vol. 10, no. 5, pp. 453-470, 2007, doi: $10.1002 /$ we. 235 .

[42] K. T. Bradford, D. R. L. Carpenter, Jr., and B. L. Shaw, 'Forecasting southern plains wind ramp events using the WRF model at 3-km', in AMS Student Conference, Atlanta, Georgia, 2010, vol. 128, no. 3, pp. 247-253, doi: 10.1016/0378-1097(95)00100-J.

[43] L. M. Focken U, 'Wind Power Forecasting Pilot Project in Alberta', energy \& meteo systems GmbH, Oldenburg, Germany, 2008.

[44] H. Zheng and A. Kusiak, 'Prediction of Wind Farm Power Ramp Rates: A Data-Mining Approach', J. Sol. Energy Eng., vol. 131, no. 3, p. 031011, 2009, doi: 10.1115/1.3142727.

[45] W. J. Ferreira C, Gama J, Matias L, Botterud A, 'A survey on wind power ramp forecasting', Argonne Natl. Lab.(ANL), Argonne, (United States), 2011.

[46] C. Kamath, 'Using Simple Statistical Analysis of Historical Data to Understand Wind Ramp Events', 2010, doi: 10.1109/TDC.2010.5484508.

[47] M. Cui, J. Zhang, C. Feng, A. R. Florita, Y. Sun, and B. M. Hodge, 'Characterizing and analyzing ramping events in wind power, solar power, load, and netload', Renew. Energy, vol. 111, pp. 227-244, 2017, doi: 10.1016/j.renene.2017.04.005.

[48] R. Billinton, R. Karki, and A. Kumar Verma, Reliability and Risk Evaluation of Wind Integrated Power Systems, Reliable and Sustainable Electric Power and Energy Systems Management, The first. Springer, 2013.

[49] S. J. Wellby and N. A. Engerer, 'Categorizing the meteorological origins of critical ramp events in collective photovoltaic array output', J. Appl. Meteorol. Climatol., vol. 55, no. 6, pp. 1323-1344, 2016, doi: 10.1175/JAMCD-15-0107.1.

[50] M. S. Eltohamy, M. S. A. Moteleb, H. Talaat, S. F. Mekhemar, and W. Omran, 'Power System Flexibility Metrics Review with High Penetration of Variable Renewable Generation', Int. J. Inf. Technol. Appl., vol. 8, no. 1, pp. 21-46, 2019.

[51] M. S. Eltohamy, M. S. A. Moteleb, H. Talaat, S. F. Mekhemar, and W. Omran, 'Technical Investigation for Power System Flexibility', in 6th International Conference on Advanced Control Circuits and Systems (ACCS) \& 2019 5th International Conference on New Paradigms in Electronics \& information Technology (PEIT), 2019, pp. 299309, doi: 10.1109/ACCS-PEIT48329.2019.9062862.

[52] A. Bossavy et al., 'Forecasting Uncertainty Related to Ramps of Wind Power Production', in European Wind Energy Conference and Exhibition 2010, EWEC 2010, 2010, p. 9, [Online]. Available: https://hal-minesparistech.archives-ouvertes.fr/hal-00765885.

[53] C. Kamath, 'Associating weather conditions with ramp events in wind power generation', 2011 IEEE/PES Power Syst. Conf. Expo. PSCE 2011, 2011, doi: 10.1109/PSCE.2011.5772527.

[54] C. Gallego, A. Costa, and A. Cuerva, 'Improving short-term forecasting during ramp events by means of RegimeSwitching Artificial Neural Networks', Adv. Sci. Res., vol. 6, no. September 2010, pp. 55-58, 2011, doi: 10.5194/asr-6-55-2011.

[55] H. Zareipour, D. Huang, and W. Rosehart, 'Wind power ramp events classification and forecasting: A data mining approach', IEEE Power Energy Soc. Gen. Meet., no. July 2011, 2011, doi: 10.1109/PES.2011.6039625. 
[56] R. Girard et al., 'Forecasting Ramps of Wind Power Production at different time scales To cite this version : HAL Id : hal-00772198 Forecasting Ramps of Wind Power Production at different time scales', 2017.

[57] Q. Yang et al., 'Evaluation of WRF-predicted near-hub-height winds and ramp events over a pacific northwest site with complex terrain', J. Appl. Meteorol. Climatol., vol. 52, no. 8, pp. 1753-1763, 2013, doi: 10.1175/JAMCD-12-0267.1.

[58] A. Fernandez, C. M. Aliaz, A. M. Gonzalez, J. Diaz, and J. R. Dorronsoro, 'Diffusion methods for wind power ramp detection', in Advances in Computational Intelligence 12th International Work-Conference on Artificial Neural Networks, IWANN, June 12-14, 2013, no. Part1, p. 106:113, doi: 10.1007/978-3-642-38679-4.

[59] A. Suzuki et al., 'Use of Offsite Data to Improve Short Term Ramp Forecasting', 11th Wind Integr. Work., vol. 9, pp. 1-6, 2012.

[60] P. P. Revheim and H. G. Beyer, 'Offshore ramp forecasting using offsite data', in EERA DeepWind 2014 deep sea offshore wind R\&D conference, 2014.

[61] J. Heckenbergerova, P. Musilek, and J. Marek, 'Analysis of Wind Speed and Power Time Series Preceding Wind Ramp Events', in Proceedings of the 15th international scientific conference on electric power engineering (EPE), 2014, vol. 57, no. 2, pp. 279-283, doi: 10.1109/EPE.2014.6839490.

[62] M. Abuella and B. Chowdhury, 'Forecasting Solar Power Ramp Events Using Machine Learning Classification Techniques', 2018 9th IEEE Int. Symp. Power Electron. Distrib. Gener. Syst. PEDG 2018, pp. 1-6, 2018, doi: 10.1109/PEDG.2018.8447599.

[63] D. Gan and D. Ke, 'Wind Power Ramp Forecasting Based on Least-Square Support Vector Machine', Energy Eng. Environ. Eng., vol. 535, pp. 162-166, 2014, doi: 10.4028/www.scientific.net/AMM.535.162.

[64] N. Cutler, 'Final report on UNSW Project for AEMO to develop a prototype wind power forecasting tool for potential large rapid changes in wind power', no. January, 2011, doi: 10.1007/s10620-009-1103-y.

[65] C. Gallego-Castillo, A. Cuerva-Tejero, and O. Lopez-Garcia, 'A review on the recent history of wind power ramp forecasting', Renew. Sustain. Energy Rev., vol. 52, pp. 1148-1157, 2015, doi: 10.1016/j.rser.2015.07.154.

[66] M. Sherry and D. Rival, 'Meteorological phenomena associated with wind-power ramps downwind of mountainous terrain', J. Renew. Sustain. Energy, vol. 033101, no. 7, pp. 1-13, 2015, doi: 10.1063/1.4919021.

[67] L. Y. Musilek P, 'Forecasting of wind ramp events - analysis of cold front detection', in 31th international symposium on forecasting.

[68] Truewind and A. W. S, 'AWS Truewind's final report for the Alberta forecasting pilot project', Alberta, Canada, 2008.

[69] B. S.Everitt and A. Skrondal, The Cambridge Dictionary of Statistics, Fourth edi. Cambridge University Press, 2010.

[70] C. Mihai, I. Lepadat, E. Helerea, and D. Călin, 'Load curve analysis for an industrial consumer', Proc. 12th Int. Conf. Optim. Electr. Electron. Equipment, OPTIM, no. 3, pp. 1275-1280, 2010, doi: 10.1109/OPTIM.2010.5510494.

[71] 'Elia, Belgium's electricity transmission system operator', 2019. http://www.elia.be/en/grid-data/powergeneration/wind-power (accessed Jul. 31, 2019).

\section{BIOGRAPHY OF AUTHORS}

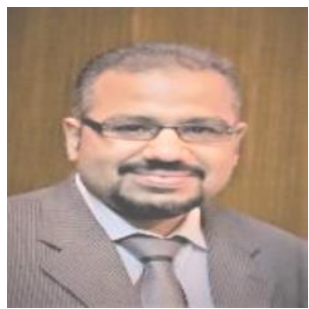

Mohammed Saber Eltohamy Research Assistant at Department of Power Electronics and Energy Conversion, Electronics Research Institute. He received the B.Sc. degree from the Faculty of Engineering at Shoubra, Benha University in 2004, and the M.Sc. degree in electrical engineering from Cairo University in 2014. He is a Ph.D. student at Ain Shams University, Cairo, Egypt. His research interests include Planning and Operation of Power Systems, Integration of Renewable Energy Systems, Distributed Generation, and Energy Management.

Email: mohammed_saber@eri.sci.eg

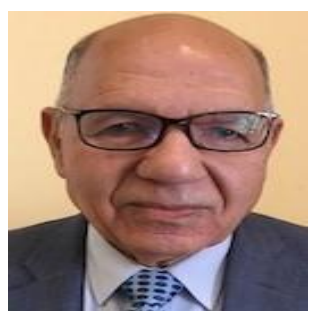

Mohammed Said Abdel Moteleb Professor at Department of Power Electronics and Energy Conversion, Electronics Research Institute. He received his B.Sc. And M.Sc. degrees from Cairo University, Cairo, Egypt in 1971 and 1978 respectively, and his Ph.D. degree from the Faculty of Electrical Engineering and information technology, Slovak Technology University, Slovakia in 1986. Prof. Moteleb is one of the leading editors-in-chief of the journal of electrical systems and information technology. His research interests include Control of Energy Systems and Optimization Techniques.

Email: moteleb@eri.sci.eg 

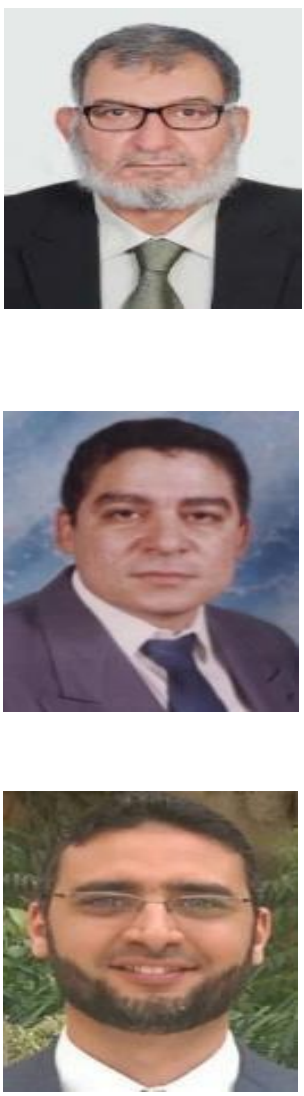

Hossam Talaat Professor at the Electrical Engineering Department at Future Univerity in Egypt. He was the former Head of the Electrical Power Engineering Department, Faculty of Engineering, Ain Shams University, Cairo, Egypt. He received his B.Sc. And M.Sc. degrees from Ain Shams University, Cairo, Egypt in 1975 and 1980 respectively, and his Ph.D. degree from the University of Grenoble, France in 1986. His research interests include Distributed Generation and Microgrids, Application of artificial intelligence techniques to Power System analysis, control, and protection; Real-time applications to electrical power systems and machines; Application of optimal and adaptive control techniques.

Email: hossam.eldeen@fue.edu.eg

Said Fouad Mekhemar received the B.Sc. degree in electrical engineering from Ain Shams University, Cairo, Egypt, in 1993, and the Ph.D. degree from the Dalhousie University, Canada, in 2002. He is currently a Professor at the Electrical Engineering Department at Future Univerity in Egypt.

Email: said_fouad@eng.asu.edu.eg

Walid A. Omran received the B.Sc. and M.Sc. degrees in electrical engineering from Ain Shams University, Cairo, Egypt, in 1998 and 2005, respectively, and the Ph.D. degree from the Department of Electrical and Computer Engineering, University of Waterloo, Canada, in 2010. Currently, he is an associate professor at the German University in Cairo. His research interests include planning and operation of smart grids, integration of renewable energy systems and energy storage systems.

Email: walid.omran@fue.edu.eg 